\title{
Experimental study on the difference of heat transfer characteristics between vertical and horizontal flows of supercritical pressure water
}

\author{
Xianliang LEI ${ }^{* 1}$, Huixiong LI $^{1}$, Weiqiang Zhang ${ }^{1}$, Nam T. Dinh ${ }^{2}$, Yumeng Guo ${ }^{1}$, Shuiqing Yu ${ }^{1}$ \\ ${ }^{1}$ State Key Laboratory of Multiphase Flow in Power Engineering, Xi'an Jiaotong University, China \\ ${ }^{2}$ Department of Nuclear Engineering, North Carolina State University, USA \\ *xianlianglei@mail.xjtu.edu.cnＴel: +86-29-82665870 Fax: +86-29-82669033
}

\section{ABSTRACT}

The present paper is devoted to investigating the difference of heat transfer characteristics between horizontal and vertical upward flows of supercritical pressure water. Experimental study is conducted with both horizontal and vertical upward tubes $(\varnothing 32 \mathrm{~mm} \times 3 \mathrm{~mm})$, covering a range of mass fluxes $(G)$ from 200 to 600 $\mathrm{kg} \cdot \mathrm{m}^{-2} \cdot \mathrm{s}^{-1}$, heat fluxes $(q)$ up to $400 \mathrm{~kW} \cdot \mathrm{m}^{-2}$, and pressure $(P)$ from 23 to $28 \mathrm{MPa}$. Heat transfer characteristics are analyzed in detail for selected parameters. The results show at low $q / G$, an apparent heat transfer enhancement and insignificant difference in the two arrangements. However, when the $q / G$ increases to a higher value (i.e. $q / G>0.5)$, heat transfer deterioration occurs and a noticeable heat transfer discrepancy is detected, where the inner-wall temperature of vertical flow far exceeds that of horizontal flow. Dimensionless parameters, $\mathrm{Bo}^{+}, \mathrm{Kv}$, and $\mathrm{BTH}$ are adopted to analyze the effects of buoyancy force and thermal acceleration for both flows. The analysis suggests that mechanisms governing horizontal and vertical flows of supercritical 
pressure water are different at high $q / G$ or in deteriorated heat transfer mode. For the vertical flow, thermal acceleration play a leading role, while for the horizontal flow, the effect of buoyancy plays a larger effect than that for vertical flow.

\section{Introduction}

Supercritical fluids can be widely used in many advanced single-phase thermosiphons as a working medium due to its high convective heat transfer coefficient and efficiency. For instance, supercritical water-cooled nuclear reactors (SCWRs) [1]; supercritical coal-fired power plants [2]; superconducting electromagnets cooling by using near-critical helium [3]; liquid rocket engines and air-breathing engines cooling by using supercritical liquid-hydrocarbon coolants and fuels [4]. In these advanced systems, thermo-hydraulic characteristics of supercritical fluids are undoubtedly one of the major concerns.

It is known that boundaries between gas phase and liquid phase disappear when the pressure exceeds the critical point. Thermo-physical properties of the fluid dramatically vary within a narrow temperature range through the pseudo-critical temperature (Pseudo-critical temperature is somehow similar to critical point $\left(P_{\mathrm{c}}=22.064 \mathrm{MPa}, t_{\mathrm{pc}}=373.9^{\circ} \mathrm{C}\right)$. The pseudo-critical temperature $\left(t_{\mathrm{pc}}>t_{\mathrm{cr}}\right)$ corresponds to the maximum value of specific heat at a certain given pressure $\left(p_{\mathrm{pc}}>p_{\mathrm{cr}}\right)$. These sharp variations in thermo-physical properties make the heat transfer performance of supercritical pressure fluid become complex. In generally, three kinds of heat transfer modes can be observed in the previous studies, including normal, deteriorated [5-8] 
and enhanced [9-14] heat transfer. In 2005, Pioro [15] presented a qualitative classifying criteria for these three different heat transfer modes based on the deviation of heat transfer coefficients (HTC) between the obtained experimental data and the corresponding predicting values by Dittus-Boelter (D-B) correlation [16]. At the normal heat transfer (NHT) mode, the obtaining HTCs agree well with the predicted results with D-B correlations; whereas at the enhanced heat transfer (EHT) or deteriorated heat transfer (DHT) modes, the measured HTCs are higher/lower (or the corresponding wall temperature is lower/higher) than those predicted by $\mathrm{D}-\mathrm{B}$ correlation within a part/entire of test section. In practical engineering, the DHT mode should be avoided because the wall temperature will increase rapidly and is easy to exceed the maximum allowable value of material once the heat transfer deterioration happens.

Besides, it is known that a large number of investigations on heat transfer of supercritical pressure fluid have been carried out since 1950s. Most of studies focused on the heat transfer characteristics in vertical tubes [17-29], only a small part of previous literatures concentrated on heat transfer of supercritical fluid flowing inside horizontal $[19,22,26,30-32]$ and inclined [33, 34] smooth channels. Literatures concerning on the heat transfer differences between horizontal and vertical flows are even less, thus it is hard to give quantitative results to evaluate the difference in both layouts. Yamagata [22] and Swenson [18] et. al completed experimental studies in both horizontal and vertical stainless steel tubes with I.D. of $7.5 \mathrm{~mm}$, and found that HTCs distributed uniformly along the tube circumferential direction for horizontal 
flow at low heat fluxes, which is similar to those for vertical flow. However, for the cases at higher heat fluxes, the non-uniform distribution of HTCs are shown in horizontal flow, where the HTCs at the bottom region of a horizontal tube are higher but the coefficients at the top area are lower than those for vertical flow. From the profile of variation of wall temperature in their results, it is found that there is neither sudden temperature change nor an apparent temperature peak in the pseudo-critical region even though the heat flux reached to $930 \mathrm{~kW} / \mathrm{m}^{2}$, where the corresponding ratio of $q / G$ achieves to $0.738 \mathrm{~kJ} / \mathrm{kg}$. Furthermore, heat transfer deterioration phenomenon can be clearly observed from the review of Hall and Jackson [35], as shown in Figure 1, where the variation in temperature for vertical flows in DHT mode are totally different from those for horizontal flows under similar conditions. Take line (a) and line (e) for example, the temperature profile of horizontal flow presents a wide-range peak but that in vertical tube exhibiting a narrow sharper peak when the $q / G$ ratio is in the range of $0.8-1.0 \mathrm{~kJ} / \mathrm{kg}$. It is also found that, for vertical tubes, the wall-temperature peak increases evidently with the heat flux increase, such as the line (a) and line (b). Besides, with the $q / G$ rising from 0.66 to $0.79 \mathrm{~kJ} / \mathrm{kg}$, the narrow sharper peak of wall temperature moves close to a lower enthalpy region (from 1830 $\mathrm{kJ} / \mathrm{kg}$ to $1715 \mathrm{~kJ} / \mathrm{kg}$ ). Similarly, Krasyakova et al. [19] also found the difference of heat transfer characteristics between horizontal and vertical flows in DHT cases. The temperature profile in a horizontal tube is smoother than that in a vertical tube, and the wall temperature on the upper part is always increased to a higher value than that on the lower. However, no clear explanations for this interesting phenomenon can be 
given, thus further studies for these special characteristics are needed.

(insert Figure 1)

The obvious wall-temperature discrepancy between horizontal and vertical tubes at DHT conditions also could be found in other literatures [11, 36-38], but unfortunately the heat transfer mechanism for the occurrence of deteriorated heat transfer with supercritical fluid is still not clear yet. Several explanations and debates for the mechanism of heat transfer deterioration were proposed in the past decades. Kruzhilin [39] argued that, in the pseudo-critical region or at the large value of $q / G$, certain deterioration of heat transfer for turbulent flow can be ascribed to the rapid expansion of this low-density layer near the wall due to a drastic decrease of density as the temperature increases, leading to flow velocity component that is normal to the wall rises. Kafengauz [40] proposed a mechanism for "pseudo-boiling" after analyzing data of different fluids by assuming that the low-density layer near wall was destroyed when the individual volumes of the low-density fluid entrained into the cooler core of the high-density flow. Yu [41] and Bazargan [42] believed that the buoyancy force has an important effect to heat transfer of turbulent flow. They found that the reinforced buoyancy in a larger diameter horizontal tube (ID=26mm) would result in a higher wall temperature difference $(\Delta \mathrm{T})$ compared to the smaller diameter tube.

Furthermore, according to the numerical analyses on heat transfer of vertical and horizontal flows given by Wen et. al [43], Xiong and Cheng [44] and Lei et al[45], the mechanism of the DHT occurrence in both vertical upward and horizontal flows are generally attributed to the influence of intensified buoyancy force, thermal 
acceleration and their combined effect due to the steep variation of thermal-physical properties near the pseudo-critical point. Owing to the transformation of flow direction, the effect of buoyancy and thermal acceleration varies simultaneously, which makes the heat transfer mechanism in both flows completely different. For vertical upward flow at supercritical pressures, the enhanced thermal acceleration and buoyancy force are combined and taken action in identical flow directions that may result in remarkable high wall-temperature in some local sections. But for horizontal flow, the intensive thermal acceleration and buoyancy force are taken effect in the axial and perpendicular direction, making the wall-temperature non-uniform in a wall-orthogonal cross-section of the tube. Apparently, these numerical proved findings can provide qualitative evidence for its mechanism but it still needs quantitatively experimental evaluation for the affection of buoyancy and thermal acceleration in both flows, especially in the DHT mode.

Therefore, a systematic experiment was respectively conducted in both horizontal and vertical tubes with the diameter of $\varnothing 32 \mathrm{~mm} \times 3 \mathrm{~mm}$ under the operating conditions including low mass fluxes from 200 to $600 \mathrm{~kg} \cdot \mathrm{m}^{-2} \cdot \mathrm{s}^{-1}$, heat fluxes up to $400 \mathrm{~kW} \cdot \mathrm{m}^{-2}$, and pressure of 23-28 $\mathrm{MPa}$. Then the distinctions of heat transfer characteristics between horizontal and vertical tubes are fully compared at various mass fluxes, heat fluxes and pressures in EHT and DHT modes. Finally, the effect of buoyancy and thermal acceleration and their combined effect are quantitatively evaluated by a few dimensionless parameters, i.e. Bo, Gr, and thoroughly analyzed and discussed. 


\section{Experimental apparatus and Data acquisition}

In the present study, the platform of High Temperature and Pressure test loop (Hi-TaP) in Xi'an Jiaotong University was employed. The schematic diagram of the experimental test loop is shown in Figure 2. The working fluid made up of distilled and de-ionized water is pumped from a water tank by a high pressure piston pump into the circulation system. The water is heated when passing through a regenerative heat exchanger, and flows in a pre-heater to be heated further to reach the specified test conditions, and then flows into the test section. Both pre-heater and test section are electrically heated by alternative currents (in the range of 0-10,000 A) with low voltages. The whole tubes are thermally insulated by glass wool to minimize the heat loss. The water from the exit of the test section flows through the regenerator and the condenser, and then returns to the feed water tank. A mass flow meter is used to measure the mass flux of water. The water temperatures at the inlet and outlet are measured by $\mathrm{NiCr}-\mathrm{NiSi}$ sheathed thermocouples.

(insert Figure 2)

A smooth $\Phi 32 \mathrm{~mm} \times 3 \mathrm{~mm}$ circular stainless steel tube is employed in the present study. (insert Figure 3 shows a schematic diagram of the layout of wall temperature measuring points installed on the outer surface of the test section tubes. Test section is connected to an unheated tube with a length of $1.5 \mathrm{~m}(\mathrm{~L} / \mathrm{D}>50)$ to allow for the full-development of the flow in the tube. Along the flow direction of the test tube, 
seven cross-sections in horizontal tube and nine sections in vertical upward tube are arranged to measure the outer wall surface temperatures. There are totally 40 $\mathrm{NiCr}-\mathrm{NiSi}$ K-type thermocouples $(\Phi 0.2 \mathrm{~mm})$ welded on the outer surface of each tested tube to measure the temperature distributions on the outside wall of the test sections. Two different arrangements of thermocouples in each cross-section are applied according to its feature of temperature distribution. As can be seen in (insert Figure 3, for the horizontal tube, eight thermocouples are evenly distributed in section 5-7, but in section 1-4, four thermocouples are evenly furnished in each section. As for vertical tube, there are 4 thermocouples installed in front sections, such as 1 7, and the number of thermocouples increases to 6 at section 8 and 9 . A series of $\Phi 3 \mathrm{~mm}$ $\mathrm{NiCr}-\mathrm{NiSi}$ armored thermocouples are protruded into the inlet and outlet of the test section to measure the bulk fluid temperature. The fluid gauge pressure at the inlet of the test section is measured by Rosemount 3051 capacitance-type pressure transmitters, while the pressure drop of the test section is measured by a 3051 capacitance-type differential pressure transducer.

(insert Figure 3)

In Hi-Tap platform, a three-point heating method was applied in pre-heater, the schematic diagram of heating mode and signal transmission are shown in (insert Figure 4. The electrical signals are obtained from different sensors through current/voltage transducer and transformer, and then sent into a data acquisition system (DAS). All types of transient signals collecting from sensors and pertinent 
information, such as pressure, mass flux, input power, fluid temperature and outer-wall temperature were recorded by DAS utilities.

(insert Figure 4)

The uncertainties of experimental variables have been shown in Table 1.

(insert Table 1)

\subsection{Test procedure and Cases}

In the experimental process, the pressure, mass flux and heat flux in the test section were firstly controlled at predetermined operating condition. Then, one of the independent experimental parameters was changed, i.e. inlet temperature. When the flow reached to a steady state, the data acquisition system was activated to save the experimental data. After that, the heating power in the preheater was augmented progressively until the fluid at the inlet of the test section was superheated or the wall temperature went beyond the limit. During this process, the entire experimental data at different inlet fluid conditions was saved timely. The tracked signals and parameters were visually monitored to decide whether the steady state of the expected experimental condition was achieved. The corresponding operating parameters were read 30 times by the DAS and then 60 sets of transient data and a group of averaged data was saved.

A series of experiments were performed at pressures of 23-28 $\mathrm{MPa}$, mass fluxes of $200-600 \mathrm{~kg} /\left(\mathrm{m}^{2} \mathrm{~s}\right)$, and heat fluxes of $0-400 \mathrm{~kW} / \mathrm{m}^{2}$. The details can be seen in Table 2. 
(insert Table 2)

It should be noted that when the heat flux increases to a relatively higher value, the wall temperature will increase faster and may exceed the allowable limit of tube material. For example, the case with heat flux of $400 \mathrm{~kW} / \mathrm{m}^{2}$, wall temperature quickly reached $650^{\circ} \mathrm{C}$ at the bulk enthalpy of $1756 \mathrm{~kJ} / \mathrm{kg}$. Under such condition, we manually cut off the electrical supply to ensure test section's safety and stopped these kind of cases with higher heat flux, thus the experimental data shows in some figures were not covered the whole enthalpy range.

\subsection{Data reduction}

It is generally acknowledged that axial heat flux distributions of a pipe flow were assumed approximately uniform when circular tubes were heated by the passage of an electric current through the walls. However, for the horizontal pipe flows, the circumferential heat flux is non-uniform as a result of wall-temperature uneven distribution affected by buoyancy or other effect. In order to obtain the inner-wall temperature distribution of horizontal tubes at different conditions, a finite volume method was adopted. Considering infinite solutions may exist in a specific inverse-heat-conduction problem, we simplified this solving method by assuming heat flux only transferred along the circumferential direction.

The shell of the circular pipe was divided into $\mathrm{M} \times \mathrm{N}$ control volumes (as seen in (Insert Figure 5) and each volume had one representative node. Outer wall was the first layer node in the radial direction, and the inner wall was the $\mathrm{N}$ layer node. Each control volume was shown in (Insert Figure 5, where E, W, N, S denoted the positions of East, West, North and South, the conservation equation could be written as:

(Insert Figure 5) 


$$
a_{P} T_{P}=a_{E} T_{E}+a_{W} T_{W}+a_{N} T_{N}+a_{S} T_{S}+b
$$

Where,

$$
a_{E}=\frac{\Delta r}{r_{e}(\delta \theta)_{e} / \lambda_{e}}, a_{W}=\frac{\Delta r}{r_{w}(\delta \theta)_{w} / \lambda_{w}}, a_{N}=\frac{r_{n} \Delta \theta}{(\delta r)_{n} / \lambda_{n}}, a_{S}=\frac{r_{s} \Delta \theta}{(\delta r)_{s} / \lambda_{s}}
$$

The source term could be express as:

$$
b=S_{C} \Delta V=S \Delta V=S\left(0.5\left(r_{n}+r_{s}\right) \Delta r \Delta \theta\right)
$$

And its discrete form of equation (1) could be written as:

$$
T(I, J+1)=\left(a_{P} T(I, J)-a_{E} T(I+1, J)-a_{W} T(I-1, J)-a_{N} T(I, J-1)-b\right) / a_{s}
$$

In the whole calculation region, the outer-wall temperature that measured from the experiment would be used as an exterior boundary condition. On the external boundary $(\mathrm{J}=1)$, the equation ( 2 ) could be depicted as:

$$
T(I, 2)=\left(a_{P} T(I, 1)-a_{E} T(I+1,1)-a_{W} T(I-1,1)-b+q_{w} r_{0} \Delta \theta\right) / a_{s}
$$

When the temperatures in I, I+1 and I- 1 location are given, the inner layer $\mathrm{J}+1$ could be solved.

Inner-wall temperature distribution could be obtained by adapting iterative computation. Once the reasonable initial temperature field was obtained, the corresponding thermal conductivity and electrical resistance for every control volume would be re-calculated. Then the new temperature distribution by iterative computation method would be received. When the convergent requirement was reached, the iteration programme was quitted. The inner-wall temperature and inner-wall heat flux were solved.

The heat flux, a key factor in this calculation, was estimated from the imposed electric power on the test section and thermal efficiency. A thermal insulator was wrapped around the outer tube wall to minimize the heat loss. The heated tube was actually equivalent to $(\mathrm{M}-1) \times(\mathrm{N}-1)$ resistance in parallel. The corresponding heating source of each control volume could be calculated with an equation, and the electrical resistance 


$$
\widehat{Q}=U^{2} / R(I, J)
$$

Where, $R(I, J)=\rho(I, J) / F(I, J), \quad \rho$ is the electrical resistivity and $F$ is the area of control volume, $U$ is the voltage.

Volume heat source $(S)$ can be known from,

$$
S=\frac{\widehat{Q}}{\Delta V}=\frac{2 \widehat{Q}}{\left(r_{n}+r_{s}\right) \Delta r \Delta \theta}
$$

Besides, the bulk fluid enthalpies in local cross-section are linearly interpolated with both inlet and outlet enthalpy values that measured by armored thermocouples. And the corresponding local fluid temperatures at different positions are obtained through the calculation of heat balance.

\section{Results and Discussions}

Heat transfer characteristics for vertical upward and horizontal flow in both EHT and DHT mode are firstly presented. Then the effects of heat fluxes, pressures and mass fluxes on heat transfer for both flows are carefully analyzed and compared. Finally, multiple non-dimensional parameters, i.e. $B o+, G r, J$ et al, were employed to quantitatively evaluate buoyancy and thermal acceleration effect in mixed convection of supercritical flow.

\subsection{Heat transfer characteristics in EHT and DHT Modes}

A group of comparative result on heat transfer characteristics for horizontal and vertical upward flow in the EHT and DHT mode are respectively given, as shown in (insert Figure 6. (insert Figure 6 (a) depicts the variations of the inner-wall 
temperature in both flows at EHT case $(q / G=0.33 \mathrm{~kJ} / \mathrm{kg}$ ), and (insert Figure 6 (b) shows the difference of inner wall-temperature profiles in both flows at DHT case $(q / G=0.5 \mathrm{~kJ} / \mathrm{kg})$. It is noted that for horizontal flow, three different temperatures are exhibited respectively locating in the top, middle and bottom region due to their non-uniform distributions. But for vertical upward flow, temperatures are almost identical at the same tube cross-section, hence just one temperature curve is given, which can represent different generatrix along the whole tube. (insert Figure 6a and Figure 7b)

As shown in (insert Figure 6(a), when the heat flux is $200 \mathrm{~kW} / \mathrm{m}^{2}(q / G=0.33 \mathrm{~kJ} / \mathrm{kg})$, that is an EHT mode, the inner-wall temperatures for horizontal flow along the tube circumferential direction is changed smoothly but unevenly distributed. A remarkable wall temperature difference between the top, middle and bottom region of a horizontal pipe is presented. The inner-wall temperature at the top generatrix of horizontal tube always maintains to the highest value, but these values in the bottom region are exactly opposite. However, for the vertical flow, inner-wall temperature distribution is basically uniform at the same cross-section and its profile is almost the same as the middle generatrix temperature curve of the horizontal tube that is located between the top and bottom generatrix.

With the heat flux increased to $300 \mathrm{~kW} / \mathrm{m}^{2}(q / G=0.5 \mathrm{~kJ} / \mathrm{kg})$, the heat transfer mode turned into DHT in both horizontal and vertical upward flow, as shown in (insert Figure 6(b). An obvious inner-wall-temperature peak appears in the vertical tube and the top generatrix of horizontal tube, where the corresponding bulk enthalpy region is 
ranging from 1700 to $2500 \mathrm{~kJ} / \mathrm{kg}$. Compared the maximum temperatures for horizontal and vertical flow within this enthalpy range, it is found that the maximum inner-wall temperature at $q / G=0.5 \mathrm{~kJ} / \mathrm{kg}$ is clearly greater than that in the case of $q / G=0.33 \mathrm{~kJ} / \mathrm{kg}$, i.e. the value in the vertical tube is $673^{\circ} \mathrm{C}$, but the maxima is $550^{\circ} \mathrm{C}$ in the horizontal tube.

In order to find out the general distinctions between vertical upward flow and horizontal flow at various conditions, heat transfer characteristics are analyzed in detail for selected mass fluxes, heat fluxes and pressures in the following sections.

\subsection{Effect of Heat fluxes}

(insert Figure 8 shows the variation of inner-wall temperature of test sections with the increase of bulk enthalpy in both horizontal and vertical upward tubes at different heat fluxes when the pressure $(P)$ is kept as $26 \mathrm{MPa}$ and mass flux $(G)$ equals to 600 $\mathrm{kg} / \mathrm{m}^{2} \mathrm{~s}$

\section{(insert Figure 8)}

It is seen from (insert Figure 8 that, when the heat flux equals $200 \mathrm{~kW} / \mathrm{m}^{2}$ $(q / G=0.33 \mathrm{~kJ} / \mathrm{kg})$, the variation of inner-wall temperature profile for both flow are very gentle with the increasing of bulk fluid enthalpy. For the horizontal flow, a constant inner-wall temperature difference between top generatrix and bottom generatrix keeps at $25^{\circ} \mathrm{C}$. Most of inner-wall temperature points on the bottom generatrix of the horizontal tube are basically overlapped with the experimental values of vertical tube, which indicates that the heat transfer characteristics in both 
flows of supercritical pressure fluid are similar at low heat flux.

However, when the heat flux increased to $300 \mathrm{~kW} / \mathrm{m}^{2}$, the heat transfer features become sophisticated along with the occurrence of heat transfer deterioration. A noticeable sharp temperature peak of HTD can be observed in horizontal flow and the corresponding temperature difference between bottom and top generatrix is enlarged. For the vertical upward flow, a sharper temperature peak also exists, where the maximum of the inner-wall temperature arrived at $651^{\circ} \mathrm{C}$ at the enthalpy of 2115 $\mathrm{kJ} / \mathrm{kg}$, which goes beyond that of horizontal flow. The peak value of horizontal flow is $530^{\circ} \mathrm{C}$ on the top generatrix of horizontal tube at $1786 \mathrm{~kJ} / \mathrm{kg}$. Apparently, at the same conditions, the degree of deterioration of vertical flow is more serious than that of horizontal flow.

Besides, it is also found that the corresponding start enthalpy point to the location with a rapid inner-wall temperature elevation is lower than that in vertical tube. Meanwhile, the bulk enthalpy region occupied by high-temperature fluid in horizontal tube is much wider than that in vertical tube. For the horizontal flow, the bulk enthalpy region is covered from 1600 to $2500 \mathrm{~kJ} / \mathrm{kg}$, but it is only included from 1800 to $2500 \mathrm{~kJ} / \mathrm{kg}$ for vertical flow. In short, vertical tubes is more dangerous in the practical application as a result of the fact that wall temperature may firstly reach the allowable value at the same $\mathrm{q} / \mathrm{G}$ conditions, thus it should be paid more attention.

\subsection{Effect of Mass Fluxes}

(insert Figure 9 shows the comparison results of the inner-wall temperature in both 
horizontal and vertical upward tubes varying with the bulk fluid enthalpy at different mass fluxes with the pressure $(P)$ of $26 \mathrm{MPa}$ and inner-wall heat flux $(q)$ of 300 $\mathrm{kW} / \mathrm{m}^{2}$.

(insert Figure 9)

Likewise, for the horizontal flow, it is clearly seen in (insert Figure 9 that inner-wall temperature on the top generatrix is always higher than that on the bottom generatrix at different mass fluxes, and the temperature difference between top and bottom region continuously shrink as the mass flux increases. The inner wall temperature of vertical upward flow is basically similar to that in the bottom region of horizontal flow. At some low mass flux or high $q / G$ ratio cases, DHT may occur and non-uniform distribution of local temperature along the cross section circumferential direction will be presented and enlarged gradually, such as the case of $G=600 \mathrm{~kg} / \mathrm{m}^{2} \mathrm{~s}$. The inner-wall temperature on the top generatrix starts to quickly rise in the low enthalpy region $(H<1700 \mathrm{~kJ} / \mathrm{kg})$, and then the temperature profile achieves a peak. Similarly, a temperature peak also appears in the vertical upward tube at the same mass flux, where the inner-wall temperature peak value in the top region of horizontal channel is about $552^{\circ} \mathrm{C}$ at enthalpy of $2313 \mathrm{~kJ} / \mathrm{kg}$, while the wall temperature peak on vertical tube is about $653^{\circ} \mathrm{C}$ at bulk enthalpy of $2120 \mathrm{~kJ} / \mathrm{kg}$.

The reason for this phenomenon can be ascribed to the variation of buoyancy [41]. With the mass fluxes increasing, axis momentum of the working fluid will be enhanced and the corresponding buoyancy effect on heat transfer will be weakened. In 
a word, with the increasing of mass fluxes, the heat transfer performance will be improved for both horizontal and vertical upward flows.

\subsection{Effect of Pressures}

(insert Figure 10 shows the variation of the inner-wall temperature in both horizontal and vertical upward flows with the increase of bulk enthalpy at different pressures when the heat flux $(q)$ is $300 \mathrm{~kW} \cdot \mathrm{m}^{-2}$ and mass flux $(G)$ is $600 \mathrm{~kg} \cdot \mathrm{m}^{-2} \cdot \mathrm{s}^{-1}$.

(insert Figure 10)

As shown in (insert Figure 10, at all pressures, temperature peaks and heat transfer deterioration can be observed in both tubes. However, some evident differences in temperature distribution between horizontal and vertical upward flows are exhibited. First of all, for vertical flow, the peak temperature, occurring at the bulk enthalpy of $2150 \mathrm{~kJ} / \mathrm{kg}$, moves to the higher enthalpy region and decreases gradually with the increase of pressure. When the pressure is $23 \mathrm{MPa}$, the wall-temperature peak reaches to $673^{\circ} \mathrm{C}$ in an axial position corresponding to the bulk enthalpy of $2100 \mathrm{~kJ} / \mathrm{kg}$, which is a very dangerous to the temperature limitation of stainless steel. But when the pressure increases to $26 \mathrm{MPa}$, the peak is reduced to $652^{\circ} \mathrm{C}$ in the position corresponding to the bulk enthalpy of $2120 \mathrm{~kJ} / \mathrm{kg}$. The wall temperature peak continually decreases to $590^{\circ} \mathrm{C}$ in the position corresponding to the bulk enthalpy of $2186 \mathrm{~kJ} / \mathrm{kg}$ if pressure increased to $28 \mathrm{MPa}$. For the horizontal flow, with the pressure increasing, the non-uniform distribution of temperature along the circumferential 
direction gradually reduced. The higher the pressure is, the smaller the temperature difference between top and bottom generatrix is, which mainly happens in the region where enthalpy is above $1500 \mathrm{~kJ} / \mathrm{kg}$. In both flows, with the fluid pressure increasing, the degree of heat transfer deterioration mitigates and the corresponding inner-wall temperature reduces owing to the gentle variation of thermal-physics properties at higher pressures.

\subsection{Analysis of heat transfer mechanism between horizontal and vertical flow}

As mentioned above, the difference of heat transfer feature between the horizontal tube and vertical upward tube is remarkable, especially in the DHT mode. Some previous studies [41, 46, 47] pointed out that acceleration and buoyancy effect are significantly important for HTD, turbulent convective heat transfer changes with above effects. In order to obtain these effects on heat transfer of supercritical pressure fluids, a few common dimensionless numbers have been introduced, such as $\mathrm{Bo}+$ number (Eq. 5), $K v$ (Eq. 6) and $J$ number (Eq. 7), for evaluating the effect of buoyancy and thermal acceleration at different working conditions.

Jackson et al. [48, 49] derived an order-of-magnitude criterion for the onset of buoyancy effects in fully developed turbulent pipe flow by modifying the turbulent shear-stress profile across the viscous layer. According to the criterion, for

$$
B o^{+}=\frac{G r_{q}}{\mathrm{Re}_{b}^{3} \cdot \mathrm{P}_{b} \mathrm{r}^{0}}<5 \cdot \odot \mathrm{T}^{\top} \mathrm{C}
$$

Where $\operatorname{Re}=\frac{\bar{u} d}{v}, G r=\frac{\left(\rho_{w}-\rho_{b}\right) \rho_{b} D_{h}^{3}}{v^{2}}$. The Re number, which equals the ratio of 
inertia to viscous force acting on the fluid. The Grashof number $(G r)$, which approximates the ratio of buoyancy to viscous forces, is a dimensionless number in fluid dynamics and heat transfer.

McEligot et al [50] proposed the flow-acceleration parameter $(K v)$ as

$$
K v=\frac{v_{b}}{u_{b}{ }^{2}} \frac{d u_{b}}{d x}=\frac{v_{b}}{u_{b}} \frac{P}{\rho R T_{b}^{2}} \frac{d T_{b}}{d x}=\frac{4 q_{w}{ }^{\prime \prime} D_{i}}{\operatorname{Re}_{b}^{2} \mu_{b} C_{p b} T_{b}} \approx \frac{4 q+}{\operatorname{Re}_{b}}
$$

Where $\mathrm{q}+$ is the non-dimensional heat flux, defined as

$q^{+}=\frac{q_{w}{ }^{\prime \prime} \beta_{b}}{G C_{p b}}$

It indicates that, for $q+<0.0005$, the Nusselt number reduces by less than $5 \%$.

Petukhov and Polyakov [51]built another criterion for evaluating the mixed effect of buoyancy and thermal acceleration.

$$
B T H=\frac{G r+J}{4 \times 10^{-4} \operatorname{Re}_{b}^{2.8} \operatorname{Pr}_{b}^{1.2}}<1
$$

Where $G r=g \bar{\beta} q_{w} d^{4} / v_{f}^{2} \lambda_{f}, J=4 \frac{\operatorname{Re}}{\operatorname{Pr}}\left(\frac{q_{w} d}{\lambda_{f}} \bar{\beta} \frac{\rho_{f}}{\tilde{\rho}}\right)^{2}, \bar{\beta}=\frac{1}{\tilde{\rho}} \frac{\rho_{f}-\rho_{w}}{T_{w}-T_{f}}, \operatorname{Pr}=\frac{h_{w}-h_{f}}{T_{w}-T_{f}} \frac{\mu_{f}}{\lambda_{f}}$,

the Gr and $\mathrm{J}$ denote the buoyancy and thermal acceleration respectively.

(insert Figure 11 shows the variation of the Bo+ number with the bulk enthalpy in both horizontal and vertical tubes at different heat fluxes with pressure of $26 \mathrm{MPa}$ and mass flux of $600 \mathrm{~kg} / \mathrm{m}^{2} \mathrm{~s}$. In (insert Figure 11, it would be helpful if the Y-axis is scaled with logarithmic function.

(insert Figure 11)

It can be found from (insert Figure 11 that the variations of $\mathrm{Bo}^{+}$number with bulk enthalpy in circular channels with different orientations are different. For the 
horizontal flow, firstly, the value of $\ln (B o)$ varies slowly, and then quickly increases to a maximum when the bulk enthalpy approximates to $1800 \mathrm{~kJ} / \mathrm{kg}(q / G=200 / 600 \mathrm{~kJ} / \mathrm{kg})$ or $1600 \mathrm{~kJ} / \mathrm{kg}(q / G=300 / 600 \mathrm{~kJ} / \mathrm{kg})$. Finally, the profile of $\ln (B o)$ decreases continually with the increase of bulk enthalpy. Overall, the variation trends along the whole $\ln (\mathrm{Bo})$ curve at various heat fluxes are similar. Compared with horizontal flow, a few of interesting features can be observed from vertical upward flow in (insert Figure 11. For example, the enthalpy point corresponding to temperature maximum shifts to a lower enthalpy location with the heat flux increasing, which indicates the buoyancy intensified and leads to the maximum appeared earlier. Besides, with the increase of heat flux, $\ln (\mathrm{Bo})$ decreased to a lower value near $2200 \mathrm{~kJ} / \mathrm{kg}$, which means the effect of buoyancy in vertical tube reduced. The buoyancy in horizontal is obvious stronger than that in vertical tube in the region of $2000-2400 \mathrm{~kJ} / \mathrm{kg}$. Thus we may conclude that the buoyancy of horizontal flow is totally stronger, which could be the main contribution for DHT.

(insert Figure 12 shows the variation of buoyancy part in equation (7) with the increase of bulk enthalpy and gives the difference of Grashoft number for horizontal and vertical flow at a pressure of $26 \mathrm{MPa}$ and mass flux of $600 \mathrm{~kg} / \mathrm{m}^{2} \mathrm{~s}$.

(insert Figure 12)

The buoyancy in vertical tube at different heat fluxes is generally lower than that of horizontal flow in the whole bulk enthalpy region, as seen in (insert Figure 12. The maximum of $G r / 4 \times 10^{-4} \operatorname{Re}^{2.8} \operatorname{Pr}^{1.2}$ for vertical flow equals 3.1, but for horizontal flow, 
it is 3.5 at the heat flux of $300 \mathrm{~kW} / \mathrm{m}^{2}$, which indicates the buoyancy effect in vertical tubes is a little weaker than that in horizontal tube. Similarly, the magnitude of buoyancy for vertical flow is becoming smaller than that for horizontal flow within the region from 1600 to $2400 \mathrm{~kJ} / \mathrm{kg}$.

(insert Figure 13 gives the variations of two flow-acceleration parameters (one is $K v$ that proposed by McEligot [50] and the other is $J / 4 \times 10^{-4} \operatorname{Re}^{2.8} \operatorname{Pr}^{1.2}$ that offered by Petukhov [51] with bulk enthalpy for horizontal and vertical flow at different heat fluxes under pressure of $26 \mathrm{MPa}$ and mass flux of $600 \mathrm{~kg} / \mathrm{m}^{2} \mathrm{~s}$.

\section{(insert Figure 13)}

It can be observed from （insert Figure 13(a) that the values of $K v$ for horizontal and vertical upward flow increase with bulk enthalpy smoothly, then rise quickly to attain a peak value which is close to the enthalpy of $1800 \mathrm{~kJ} / \mathrm{kg}$, and then the value of $K v$ decreases fast and gets a minimum. With the increase of heat flux, the maximum of $K v$ moves to a lower enthalpy position. At the same conditions, the magnitude of $K v$ in the vertical tube is higher than that in the horizontal tube in the region except for 2000-2400 kJ/kg, i.e. $\mathrm{q} / \mathrm{G}=300 / 600 \mathrm{~kJ} / \mathrm{kg}$, the maximum $K v$ in the horizontal tube reaches to 4.32 but it equals to 3.65 in the vertical tube. But unlike the parameter $K v$, the variation trend of parameter $\mathbf{J}$ at different conditions are completely different, as seen in (insert Figure 13(b). The profiles of $\mathrm{J}$ at low $q / G$ are basically identical, such as the case of $q / G=0.33 \mathrm{~kJ} / \mathrm{kg}$. However, the difference between horizontal and vertical pipe amplified when $q / G$ increases to a higher value, i.e. $q / G>0.4 \mathrm{~kJ} / \mathrm{kg}$. The 
peak values for vertical flow are much higher than the corresponding value for horizontal flow at different cases, especially when $q / G$ exceeds $0.42 \mathrm{~kJ} / \mathrm{kg}$, which indicates the thermal acceleration effect in vertical flow is greater than that of horizontal flow. Besides, the bulk enthalpy position that corresponding to the maximum value of parameter $\mathrm{J}$ in vertical tube agrees well with the temperature peak. As seen in Figure 7, both of them are located near $2100 \mathrm{~kJ} / \mathrm{kg}$, i.e., $H=2104 \mathrm{~kJ} / \mathrm{kg}$ at $q / G=0.42 \mathrm{~kJ} / \mathrm{kg}$ and $H=2074 \mathrm{~kJ} / \mathrm{kg}$ at $q / G=0.5 \mathrm{~kJ} / \mathrm{kg}$.

Furthermore, the mixed effect of buoyancy and thermal acceleration is assessed by the parameter of $B T H$. (insert Figure 14 shows the variation of $B T H$ with bulk enthalpy in both horizontal and vertical flows at pressure of $26 \mathrm{MPa}$ with mass flux of 600 $\mathrm{kg} / \mathrm{m}^{2} \mathrm{~s}$.

\section{(insert Figure 14)}

It is known from (insert Figure 14 that when heat flux is low, i.e. $q=200 \mathrm{~kW} / \mathrm{m}^{2}$ $(\mathrm{q} / \mathrm{G}=0.33 \mathrm{~kJ} / \mathrm{kg})$, there is a nonsignificant difference between horizontal and vertical flow, demonstrating that the mixed effect in low $q / G$ or the EHT mode is basically identical due to the small buoyancy and thermal acceleration effect, which also provides a reasonable explanation why inner-wall temperature distributions are almost identical in both flows. However, when the heat flux increases to $300 \mathrm{~kW} / \mathrm{m}^{2}(q / G=0.5$ $\mathrm{kJ} / \mathrm{kg}$ ), the temperature difference at high $q / G$ or the DHT mode is enlarged. Besides, the enthalpy point corresponding to the maximum of mixed parameter in horizontal tubes become greater than that in vertical tubes, such as the BTH value is 3.65 at the enthalpy of $2071 \mathrm{~kJ} / \mathrm{kg}$ for vertical flow but the value of $q / G$ is 3.56 at the enthalpy of 
$1573 \mathrm{~kJ} / \mathrm{kg}$ for horizontal flow. In short, the mixed effect of buoyancy and thermal acceleration is prominent when heat flux or $q / G$ is high. What's more, variation curves of the mixed parameter BTH proposed by Petukhov have a good agreement with the inner-wall temperature profile, which indicates that the Petukhov's criteria for evaluating the effect of buoyancy and thermal acceleration is more suitable than other criteria.

In order to understand the effect of buoyancy and thermal acceleration in two different flows and verify the results in our paper, a few related experimental results at high q/G ratio (data from Yamagata [22], Yu[26], Vikhrev [30], Mokry [52], Swenson [53], Herkenrath [54],) in both vertical upward and horizontal tubes have been collected and compared, as seen in Figure 14.

Figure 14 shows the relationship between buoyancy and thermal acceleration (J/Gr) with bulk enthalpy in vertical and horizontal tubes. It is found that even though the operating parameters are not the same, the $\mathrm{J} / \mathrm{Gr}$ for vertical upward flow is larger than 1.0 within the enthalpy range of $1700 \sim 2400 \mathrm{~kJ} / \mathrm{kg}$, indicated that the thermal acceleration effect is stronger than that of buoyancy effect. However, $\mathrm{J} / \mathrm{Gr}$ value is almost lower than 1.0 for horizontal flow, which turns out the buoyancy effect is greater than that of thermal acceleration. Therefore, it can be concluded that at the same conditions, thermal acceleration play a leading role for the vertical flow, while for the horizontal flow, the effect of buoyancy plays a larger effect than that for vertical flow. 


\section{Conclusions}

The present paper reports a series of supercritical water flow experiments performed for comparative analysis of heat transfer characteristics in horizontal flow and vertical flow. The tests were carried out with the tube of $\varnothing 32 \times 3 \mathrm{~mm}$ over a range of operating conditions. In order to obtain accurate inner-wall temperatures in horizontal and vertical upward tubes, a control volume computational method and some assumptions have been adopted to solve the inverse heat conduction problem.

(1) The inner-wall temperatures of the vertical flow are basically identical with the values that in bottom region of horizontal tubes at low $q / G$ cases or the EHT mode. But the inner-wall temperatures of vertical tube are higher than the middle generatrix of horizontal tube and even far exceed the maximum of the top generatrix at high $q / G$ cases or the DHT mode. As for vertical flow, the bulk enthalpy value corresponding to the maximum temperature point appears comparative higher.

(2) The effects of heat fluxes, mass fluxes and pressures on wall temperature are discussed. It is found that the higher the heat flux is, the greater the wall temperature will be. As the mass flux increases, the temperature is much lower. With the pressure rises, the corresponding maximum temperature decreases and the peaks move to the higher enthalpy region.

(3) By calculation and analysis of the $B o^{+}$number, $K v$ and $B T H$, the effects of buoyancy and thermal acceleration are revealed. For horizontal flow, the buoyancy has a large impact on the DHT. But for the vertical flow, thermal 
acceleration plays a major role for the DHT. Besides, variation curves of the mixed parameter BTH proposed by $\mathrm{kJ} / \mathrm{kg}$ have a good agreement with the inner-wall temperature profile, which indicates that the Petukhov's criteria for evaluating the effect of buoyancy and thermal acceleration is more suitable.

In order to further explain the difference between vertical upward and horizontal flow at supercritical pressures, CFD methods will be used to capture the detailed information in future studies.

\section{NOMENCLATURE}

\begin{tabular}{|c|c|}
\hline$a$ & coefficient \\
\hline$b$ & source term \\
\hline$c_{p}$ & specific heat at constant pressure, $\mathrm{J} / \mathrm{kg} \mathrm{K}$ \\
\hline$D$ & inside diameter, $\mathrm{m}$ \\
\hline$G$ & mass flux, $\mathrm{kg} / \mathrm{m}^{2} \mathrm{~s}$ \\
\hline$g$ & gravitational acceleration, $\mathrm{m} / \mathrm{s}^{2}$ \\
\hline$H$ & specific Enthalpy, kJ/kg \\
\hline$I$ & node number, $(1,2,3, \ldots, n)$ \\
\hline$J$ & node number, $(1,2,3, \ldots, \mathrm{n})$ \\
\hline$L$ & length, $\mathrm{m}$ \\
\hline
\end{tabular}




\begin{tabular}{|c|c|}
\hline$P$ & pressure, $\mathrm{MPa}$ \\
\hline$q$ & heat flux, $\mathrm{kW} / \mathrm{m}^{2}$ \\
\hline$\widehat{Q}$ & Power, W \\
\hline$r$ & radius, $m$ \\
\hline$R$ & Electrical resistance, $\Omega$ \\
\hline$S$ & Heat source term \\
\hline$T$ & temperature, $\mathrm{K}$ \\
\hline$t$ & temperature, ${ }^{\circ} \mathrm{C}$ \\
\hline$u, v$ & Velocity vector, $\mathrm{m} / \mathrm{s}$ \\
\hline$\overline{\mathrm{u}}$ & averaged velocity, $\mathrm{m} / \mathrm{s}$ \\
\hline $\mathrm{U}$ & Voltage, V \\
\hline $\mathrm{V}$ & Volume, $\mathrm{m}^{3}$ \\
\hline$x$ & location, $\mathrm{m}$ \\
\hline
\end{tabular}

\section{Greek Letters}

$\Delta$

change in variable, $\Delta \mathrm{T}, \Delta \mathrm{r}$

$\beta$

thermal expansion coefficient, $1 /{ }^{\circ} \mathrm{C}$

$\mu$

dynamic viscosity, $\mathrm{Pa} \mathrm{s}$ 
$\rho \quad$ density, $\mathrm{kg} / \mathrm{m}^{3}$

\section{Non-dimensional Numbers}

Bo Bo number

BTH Combined effect of buoyancy and thermal acceleration

Gr Grashoft number

J Acceleration effect

Kv Flow-acceleration parameter

Pr Prandtl number; $\left(\frac{\mu \mathrm{C}_{p}}{k}\right)$

Re Reynolds number; $\left(\frac{\mathrm{GD}}{\mu}\right)$

$\mathbf{q}^{+} \quad$ Non-Dimensional heat flux; $\left(\frac{q_{w}{ }^{\prime \prime} \beta_{b}}{G C_{p b}}\right)$

\section{Subscripts or superscripts}

$\begin{array}{ll}\text { b } & \text { bulk } \\ \mathrm{i} & \mathrm{i}^{\text {th }} \text { components } \\ \mathrm{pc} & \text { pseudocritical } \\ \mathrm{w} & \text { wall }\end{array}$




\section{Acknowledgements}

The authors acknowledge the support of the National Basic Research Program of China (Grant No. 2015CB251502), National Natural Science Foundation of China (Grant No. 51506170), China Postdoctoral Science Foundation (No.2015M570840), and the Fundamental Research Funds for the Central Universities.

\section{References}

[1] R.B. Duffey, I. Pioro, X. Zhou, U. Zirn, S. Kuran, H. Khartabil, M. Naidin, Supercritical Water-Cooled Nuclear Reactors (SCWRs): current and future concepts - steam cycle options Icone 16: Proceeding of the 16th International Conference on Nuclear Engineering - 2008, Vol 4, (2008) 469-477.

[2] H. Bruggemann, Q. Chen, A. Kather, G. Scheffknecht, Modern supercritical boilers, Energy and Environment, (1998) 511-529.

[3] A. Martinez, J.L. Duchateau, G.B. Mardion, A. Gauthier, B. Rousset, Supercritical Helium Cooling of a Cable-in-Conduit Conductor with an Inner Tube, Cryogenics, 34 (1994) 591-594.

[4] M. Pizzarelli, F. Nasuti, M. Oiioin, P. Roncioni, R. Votta, F. Battista, Supercritical methane heat transfer modeling in rocket engine cooling channels, in: 49th AIAA/ASME/SAE/ASEE Joint PropulsionConference, July 14, 2013 - July 17, 2013, American Institute of Aeronautics and Astronautics Inc., San Jose, CA, United states, 2013.

[5] A. Urbano, F. Nasuti, Conditions for the occurrence of heat transfer deterioration in light hydrocarbons flows, International Journal of Heat and Mass Transfer, 65 (2013) 599-609. 
[6] A. Urbano, F. Nasuti, Onset of heat transfer deterioration in supercritical methane flow channels, in, Vol. 27, American Institute of Aeronautics and Astronautics Inc., 1801 Alexander Bell Drive, Suite 500, Reston, VA 20191-4344, United States, 2013, pp. 298-308.

[7] L. Liu, Z. Xiao, X. Yan, X. Zeng, Y. Huang, Numerical simulation of heat transfer deterioration phenomenon to supercritical water in annular channel, Annals of Nuclear Energy, 53 (2013) 170-181.

[8] G. Zhang, H. Zhang, H. Gu, Y. Yang, X. Cheng, Experimental and numerical investigation of turbulent convective heat transfer deterioration of supercritical water in vertical tube, Nuclear Engineering and Design, 248 (2012) 226-237.

[9] F. ZHOU, CFD study of convective heat transfer to carbon dioxide and water at supercritical pressures in vertical circular pipes, in, McMaster University, 2014.

[10] S. Zhang, H. Gu, Z. Xiong, S. Gong, Numerical investigation on heat transfer of supercritical fluid in a vertical 7-rod bundle, Journal of Supercritical Fluids, 92 (2014) 8-15.

[11] Z. Li, Y. Wu, J. Lu, D. Zhang, H. Zhang, Heat transfer to supercritical water in circular tubes with circumferentially non-uniform heating, Applied Thermal Engineering, 70 (2014) 190-200.

[12] V.A. Kurganov, Y.A. Zeigarnik, I.V. Maslakova, Heat transfer and hydraulic resistance of supercritical pressure coolants. Part IV: Problems of generalized heat transfer description, methods of predicting deteriorated heat transfer; empirical correlations; deteriorated heat transfer enhancement; dissolved gas effects, International Journal of Heat and Mass Transfer, 77 (2014) 1197-1212.

[13] X.Y. Xu, T. Ma, M. Zeng, Q.W. Wang, Numerical study of the effects of different buoyancy models on supercritical flow and heat transfer, in: ASME 2013 Heat Transfer Summer 
Conference, July 14, 2013 - July 19, 2013, Vol. 4, American Society of Mechanical Engineers, Minneapolis, MN, United states, 2013.

[14] B. Niceno, M. Sharabi, Large eddy simulation of turbulent heat transfer at supercritical pressures, Nuclear Engineering and Design, 261 (2013) 44-55.

[15] I. Pioro, R. Duffey, Experimental heat transfer in supercritical water flowing inside channels (survey), Nuclear Engineering and Design, 235 (2005) 2407-2430.

[16] F.W. Dittus, L.M.K. Boelter, Heat Transfer in Automobile Radiators of the Tubular Type (3rd edn.), in: Publications in Engineering, University of California, Berkeley, 1930, pp. 443.

[17] M.E. Shitsman, Impairment of the heat transmission at supercritical pressure, TEPLOFIZIKA VYSOKIKH TEMPERATURE, 1 (1963) 267-275.

[18] H.S. Swenson, J.R. Carver, C.R. Kakarala, Heat Transfer to Supercritical Water in Smooth-Bore Tubes, Journal of Heat Transfer, 87 (1965) 477-483.

[19] L.Y. Krasyakova, I.I. Belyakov, N.D. Fefelova, Heat-Transfer with a Downward Flow of Water at Supercritical Pressure, Thermal Engineering, 24 (1977) 9-14.

[20] J.W. Ackerman, Pseudoboiling Heat Transfer to Supercritical Pressure Water in Smooth and Ribbed Tubes, ASME J. Heat Transfer, 92 (1970) 490-498.

[21] A.P. Ornatskiy, L.F. Glushchenko, O.F. Gandzyuk, An experimental study of heat transfer in externally-heated annuli at supercritical pressures, Heat Transfer Soviet Res., 4 (1972) 25-29.

[22] K. Yamagata, S. Yoshida, T. Fujii, S. Hasegawa, Nishikaw.K, Forced Convective Heat-Transfer to Supercritical Water Flowing in Tubes, International Journal of Heat and Mass Transfer, 15 (1972) 2575-2592.

[23] S. Ishigan, I. Kadzhin, M. Nakamoto, Heat transfer and skin friction in a water flow in tubes 
at supercritical pressure in: Heat and Mass transfer V [in Russian], Inst. Teplomassoobmena Akad. Nauk Byl. SSR, Minsk, 1 (1976) 261-269.

[24] V.A. Kurganov, Y.A. Zeigarnik, I.V. Maslakova, Heat transfer and hydraulic resistance of supercritical-pressure coolants. Part II: Experimental data on hydraulic resistance and averaged turbulent flow structure of supercritical pressure fluids during heating in round tubes under normal and deteriorated heat transfer conditions, International Journal of Heat and Mass Transfer, 58 (2013) 152-167.

[25] J.D. Jackson, K.E. Lutterodt, R. Weinberg, Experimental Studies of Buoyancy-influenced Convective Heat Transfer in Heated Vertical Tubes at Pressures Just Above and Just Below the Thermodynamic Critical Value, in: GENES4/ANP2003, Kyoto, Japan, 2003, pp. paper 1177.

[26] S. Yu, H. Li, X. Lei, Y. Feng, Y. Zhang, H. He, T. Wang, Experimental investigation on heat transfer characteristics of supercritical pressure water in a horizontal tube, Experimental Thermal and Fluid Science, 50 (2013) 213-221.

[27] P.L. Kirillov, R.S. Pomet'ko, Smirnov, Experimental study on heat transfer to supercritical water flowing in vertical tubes, in, Int. Conf. GLOBAL-205, Nuclear Energy Systems for Future Generation and Global Sustainability, Tsukuba, Japan, 2005, pp. Paper 518.

[28] M.J. Watts, Heat transfer to supercritical pressure water: mixed convection with upflow or downflow in a vertical tube, in: Victoria University of Manchester, Vol. Ph. D, Victoria University of Manchester, 1980.

[29] M. Bazargan, D. Fraser, V. Chatoorgan, Effect of buoyancy on heat transfer in supercritical water flow in a horizontal round tube, ASME J. Heat Transfer, 127 (2005) 897-902.

[30] Y.V. Vikhrev, A.S. Konkov, Solomono.Vm, I.T. Sinitsyn, Heat-Transfer in Horizontal and 
Inclined Steam-Generating Tubes at Supercritical Pressures, High Temperature, 11 (1973) 1183-1185.

[31] G. Domin, Wärmeübergang in kritischen und überkritischen Bereichen von Wasser in Rohren, Brennst-Wäirme-Kraft, 15 (1963) 527-532.

[32] X.L. Cao, Z.H. Rao, S.M. Liao, Laminar convective heat transfer of supercritical CO2 in horizontal miniature circular and triangular tubes, Applied Thermal Engineering, 31 (2011) 2374-2384.

[33] F. Yin, T.K. Chen, H.X. Li, An investigation on heat transfer to supercritical water in inclined upward smooth tubes, Heat Transfer Engineering, 27 (2006) 44-52.

[34] C.Y. Yang, J.L. Xu, X.D. Wang, W. Zhang, Mixed convective flow and heat transfer of supercritical $\mathrm{CO} 2$ in circular tubes at various inclination angles, International Journal of Heat and Mass Transfer, 64 (2013) 212-223.

[35] W.B. Hall, J.D. Jackson, A. Watson, A review of forced convection heat transfer to fluids at supercritical pressures, Proc Instn Mech Engrs, 182 (1967) 10-22.

[36] D. Huang, Z. Wu, B. Sunden, W. Li, A brief review on convection heat transfer of fluids at supercritical pressures in tubes and the recent progress, Applied Energy, 162 (2016) 494-505.

[37] B. Zappoli, D. Beysens, Y. Garrabos, Heat Transfers and Related Effects in Supercritical Fluids, Stuttgart, Germany, 2015.

[38] L. Chen, X.-R. Zhang, Heat transfer and various convection structures of near-critical CO2 flow in microchannels, (2013).

[39] G.N. Kruzhilin, Heat transfer from wall to steam flow at supercritical pressures, in: Proceedings of the 5th International Heat Transfer Conference, Tokyo, Japan, 1974, pp. 173-176. 
[40] N. Kafengauz, M. Federov, Pseudoboiling and heat transfer in a turbulent flow, Inzhenerno-Fizicheskii Zhurnal, 14 (1968) 923-924.

[41] S. Yu, H. Li, X. Lei, Y. Feng, Y. Zhang, H. He, T. Wang, Influence of buoyancy on heat transfer to water flowing in horizontal tubes under supercritical pressure, Applied Thermal Engineering, 59 (2013) 380-388.

[42] M. Bazargan, D. Fraser, Heat transfer to supercritical water in a horizontal pipe: Modeling, new empirical correlation, and comparison against experimental data, Journal of Heat Transfer, $131(2009) 1-9$.

[43] Q.L. Wen, H.Y. Gu, Numerical simulation of heat transfer deterioration phenomenon in supercritical water through vertical tube, Annals of Nuclear Energy, 37 (2010) 1272-1280.

[44] J. Xiong, X. Cheng, Turbulence modelling for supercritical pressure heat transfer in upward tube flow, Nuclear Engineering and Design, 270 (2014) 249-258.

[45] X. Lei, H. Li, Y. Zhang, W. Zhang, Effect of buoyancy on the mechanism of heat transfer deterioration of supercritical water in horizontal tubes, Journal of Heat Transfer, 135 (2013).

[46] L. Liu, Z.J. Xiao, X. Yan, X.K. Zeng, Y.P. Huang, Heat transfer deterioration to supercritical water in circular tube and annular channel, Nuclear Engineering and Design, 255 (2013) 97-104.

[47] J.L. Xu, C.Y. Yang, W. Zhang, D.L. Sun, Turbulent convective heat transfer of CO2 in a helical tube at near-critical pressure, International Journal of Heat and Mass Transfer, 80 (2015) 748-758.

[48] J.D. Jackson, Fluid flow and convective heat transfer to fluids at supercritical pressure, Nuclear Engineering and Design, (2013) 24-40.

[49] J.D. Jackson, M.A. Cotton, B.P. Axcell, Studies of mixed convection in vertical tubes, Int. J. 
Heat Fluid Flow, 10 (1989) 2-15.

[50] D.M. McEligot, C.W. Coon, H.C. Perkins, Relaminarization in tubes, Int. J. Heat Mass Transfer, 13 (1970) 431-433.

[51] B.S. Petukhov, A.F. Polyakov, Heat transfer in Turbulent Mixed Convection, Hemisphere Publishing Corporation, 1986.

[52] S. Mokry, I. Pioro, P. Kirillov, Y. Gospodinov, Supercritical-water heat transfer in a vertical bare tube, Nuclear Engineering and Design, 240 (2010) 568-576.

[53] H.S. Swenson, J.R. Carver, C.R. Kakarala, Heat Transfer to Supercritical water in Smooth-Bore Tubes, ASME J. Heat Transfer, (1965) 477-483.

[54] H. H, M.-M. P, e.a. Jung U, Forced convection Heat transfer to water at the pressure range from 140 to 250 bar, in, EUR 3658d, EURATOM, 1967. 
Table 1

\begin{tabular}{|l|l|}
\hline \multicolumn{1}{|c|}{ Variables } & \multicolumn{1}{c|}{ Uncertainty } \\
\hline Fluid temperature $/{ }^{\circ} \mathrm{C}$ & $0.195 \%$ \\
\hline Outer-Wall temperature $/{ }^{\circ} \mathrm{C}$ & $0.191 \%$ \\
\hline Pressure $/ \mathrm{MPa}$ & $0.57 \%$ \\
\hline Heat flux $/ \mathrm{kW} \cdot \mathrm{m}^{-2}$ & $3.25 \%$ \\
\hline Mass flux $/ \mathrm{kg} \cdot \mathrm{m}^{-2} \cdot \mathrm{s}^{-1}$ & $0.29 \%$ \\
\hline
\end{tabular}


Table 2

\begin{tabular}{|l|l|l|l|}
\hline & $P / \mathrm{MPa}$ & $q / \mathrm{kW} \cdot \mathrm{m}^{-2}$ & $G / \mathrm{kg} \cdot \mathrm{m}^{-2} \cdot \mathrm{s}^{-1}$ \\
\hline Vertical upward tube & $23,26,28$ & $100,200,250,300,400$ & $300,400,600,900,1200$ \\
\hline Horizontal tube & $23,26,28$ & $200,250,300,400$ & $300,400,600,900,1200$ \\
\hline
\end{tabular}




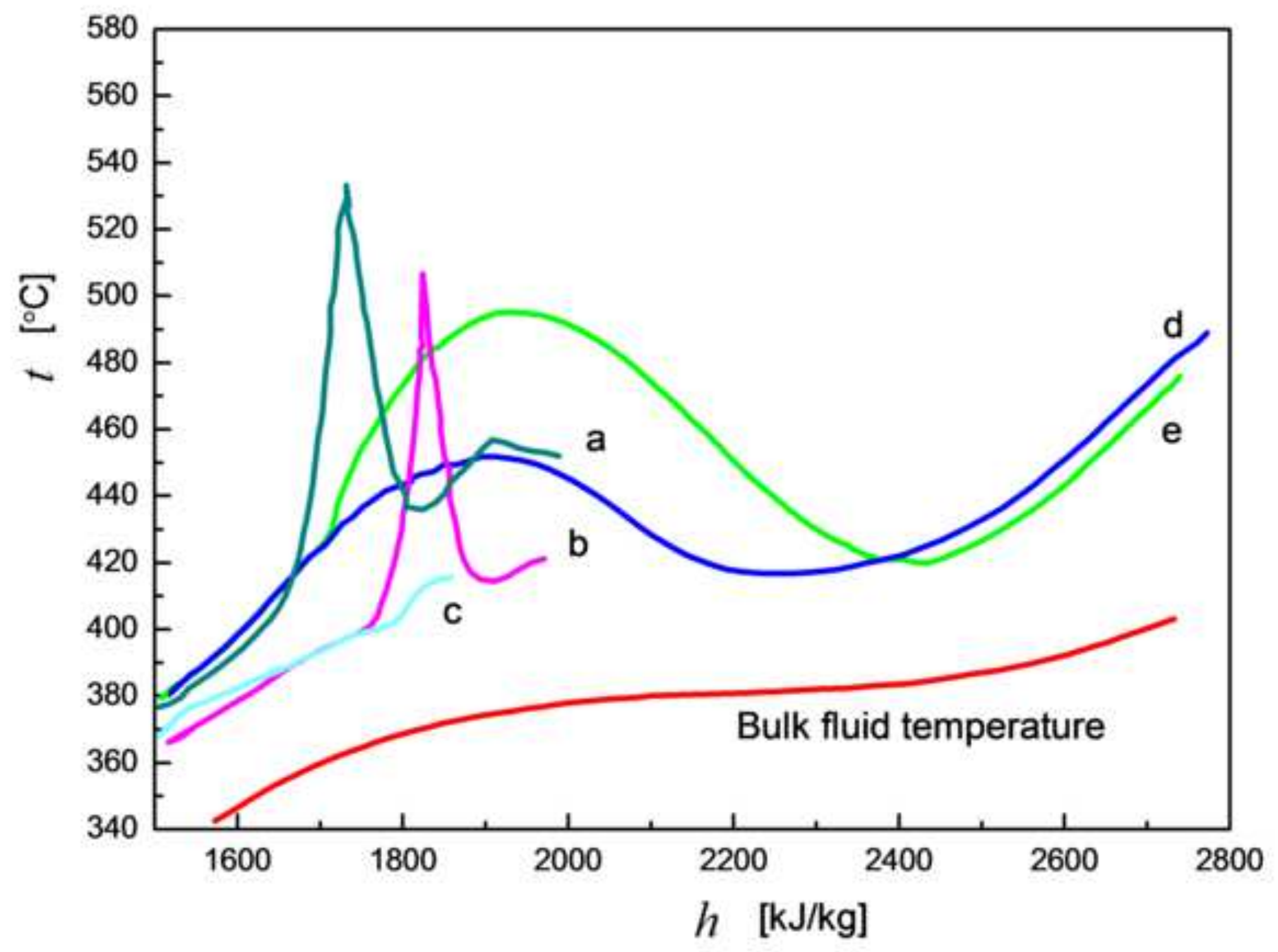




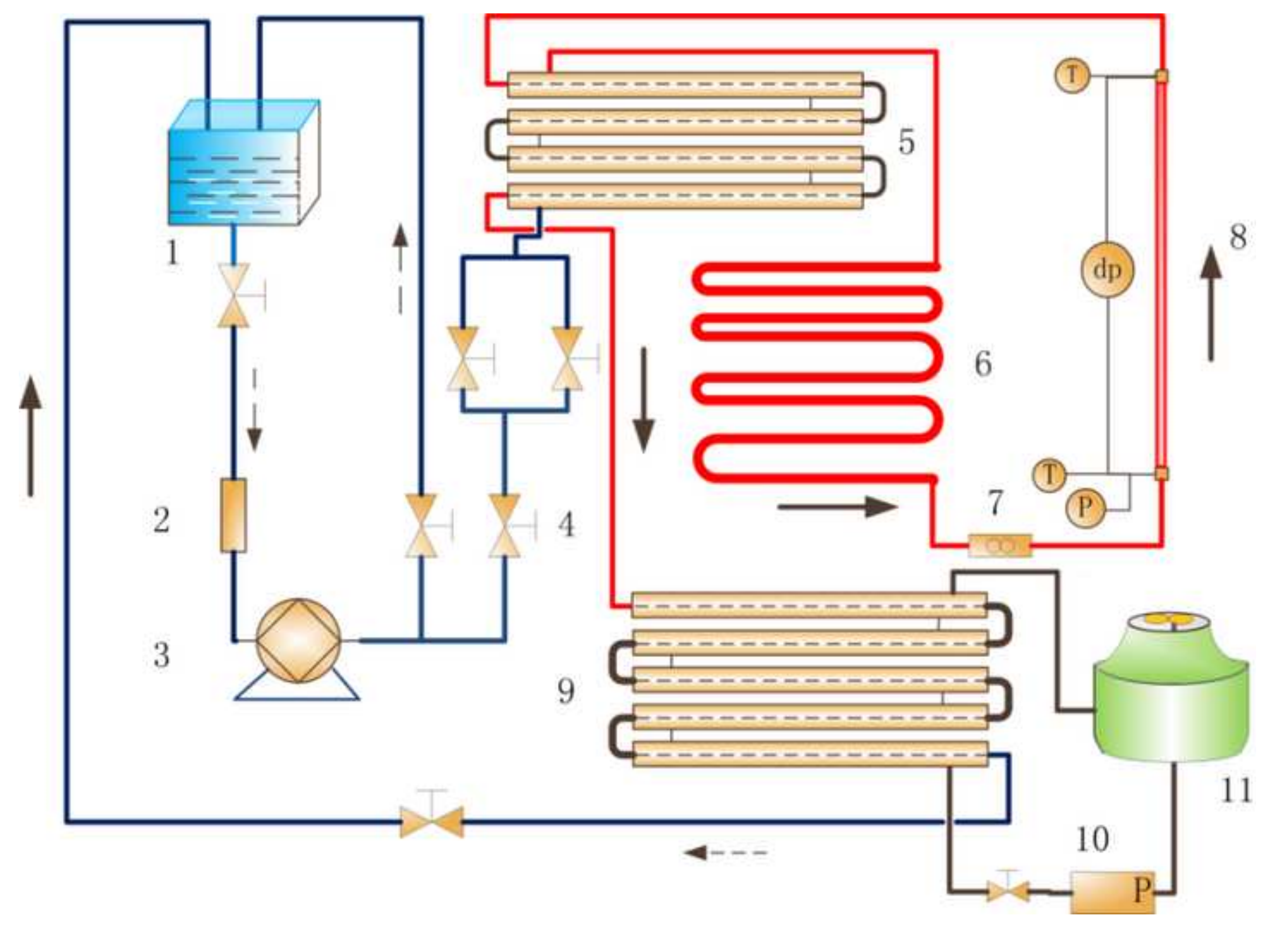<smiles>C1CCCCC1</smiles><smiles>C1CCC1</smiles>

.

.

.

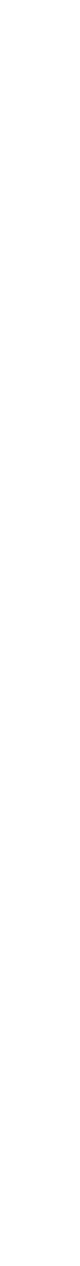




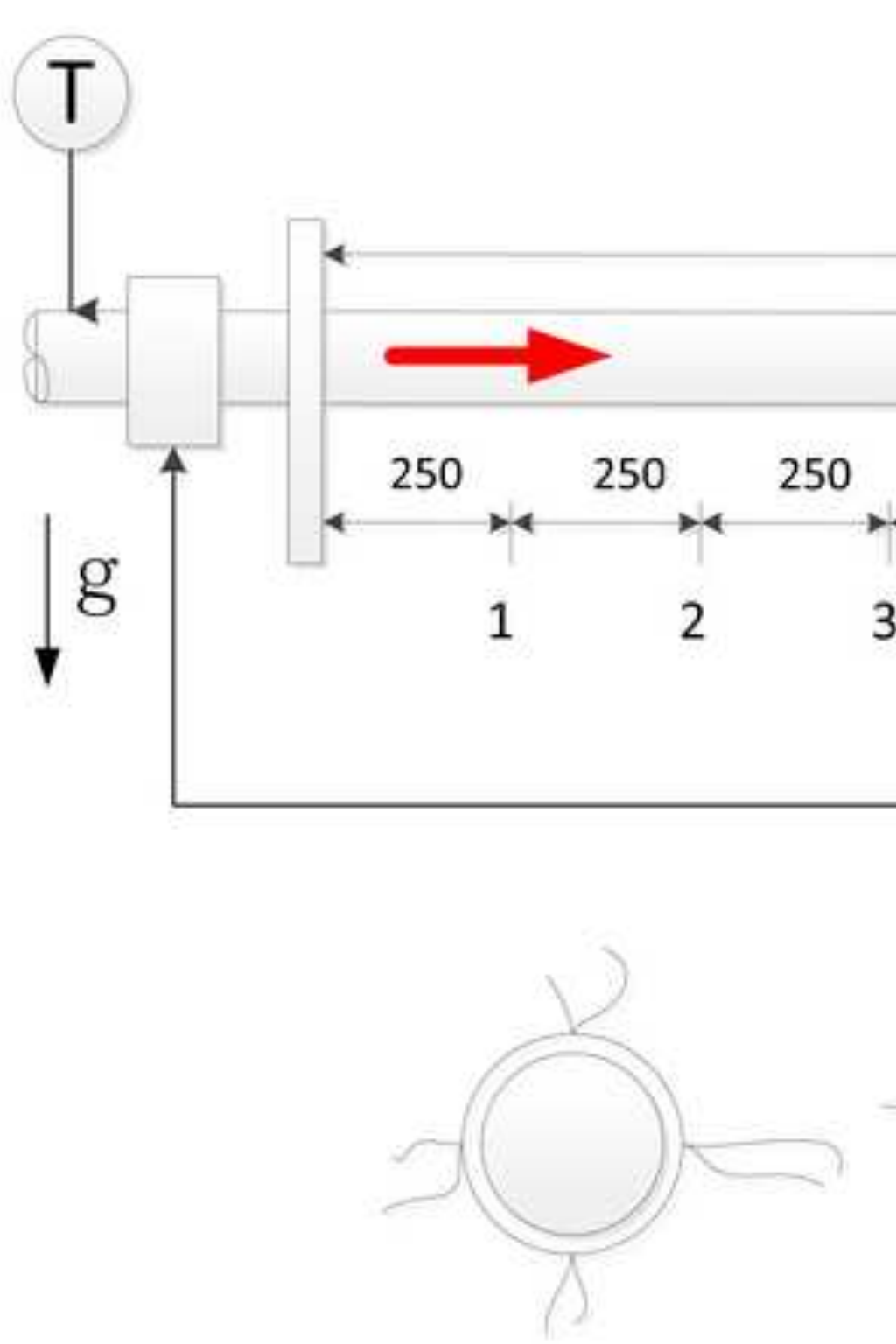

1-2 Section

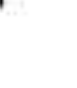

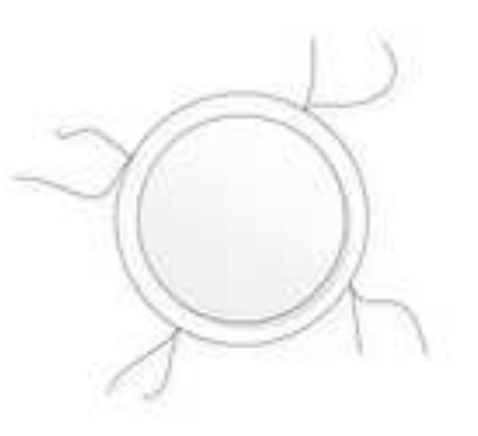

3-4 Section

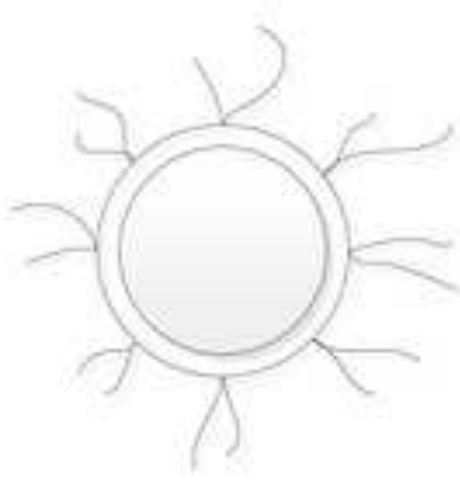

5-7 Section

\section{DP}

P

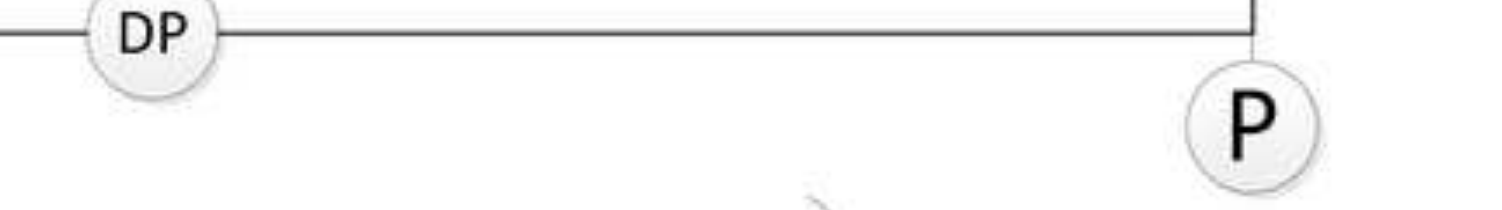

2000

$\begin{array}{lll}5 & 6 & 7\end{array}$

7

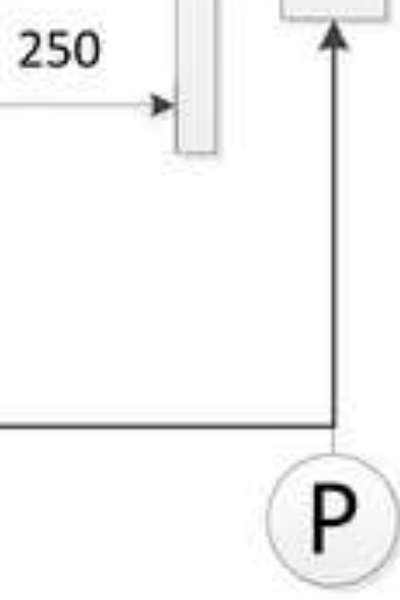


Figure $3 b$
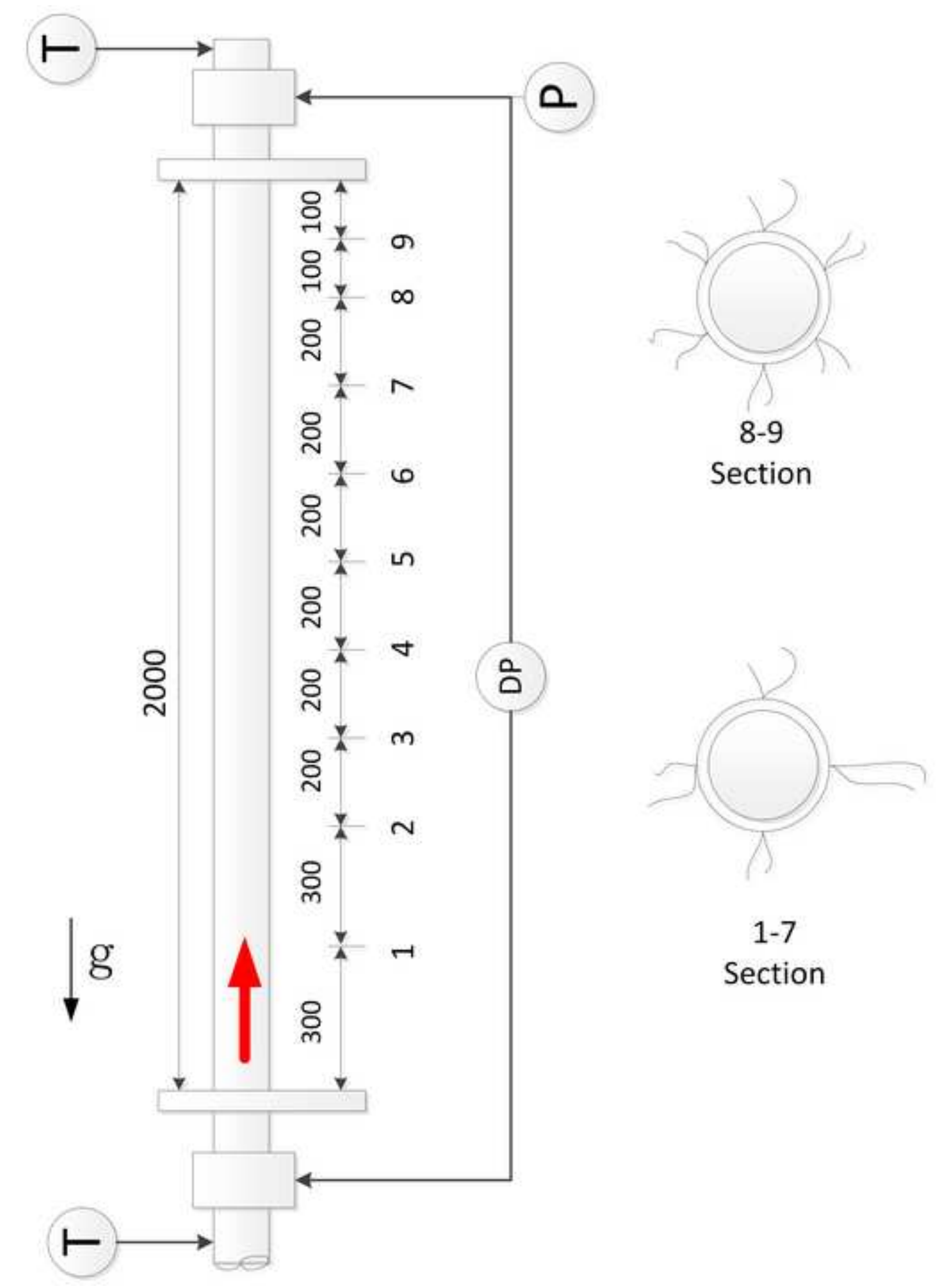


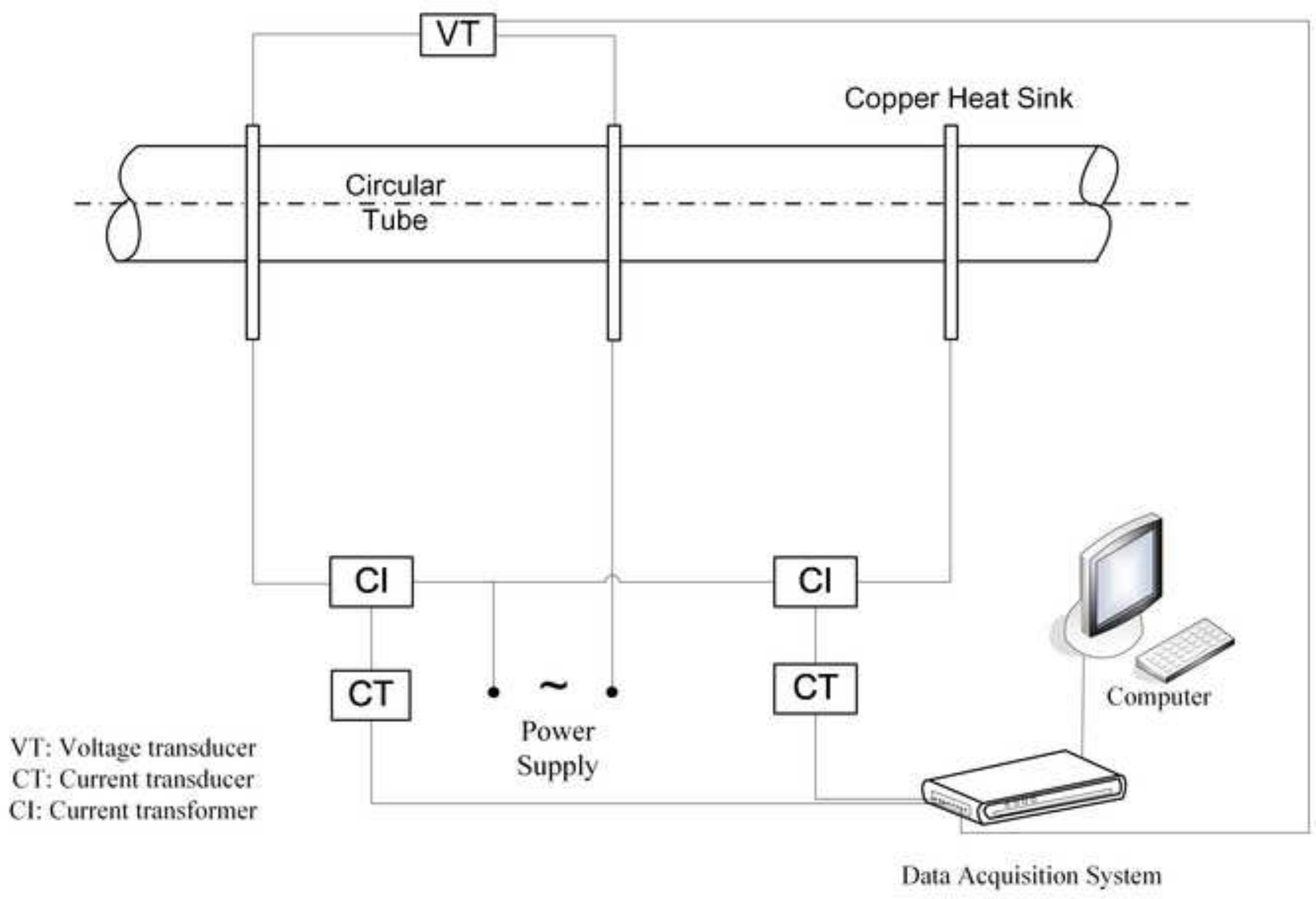




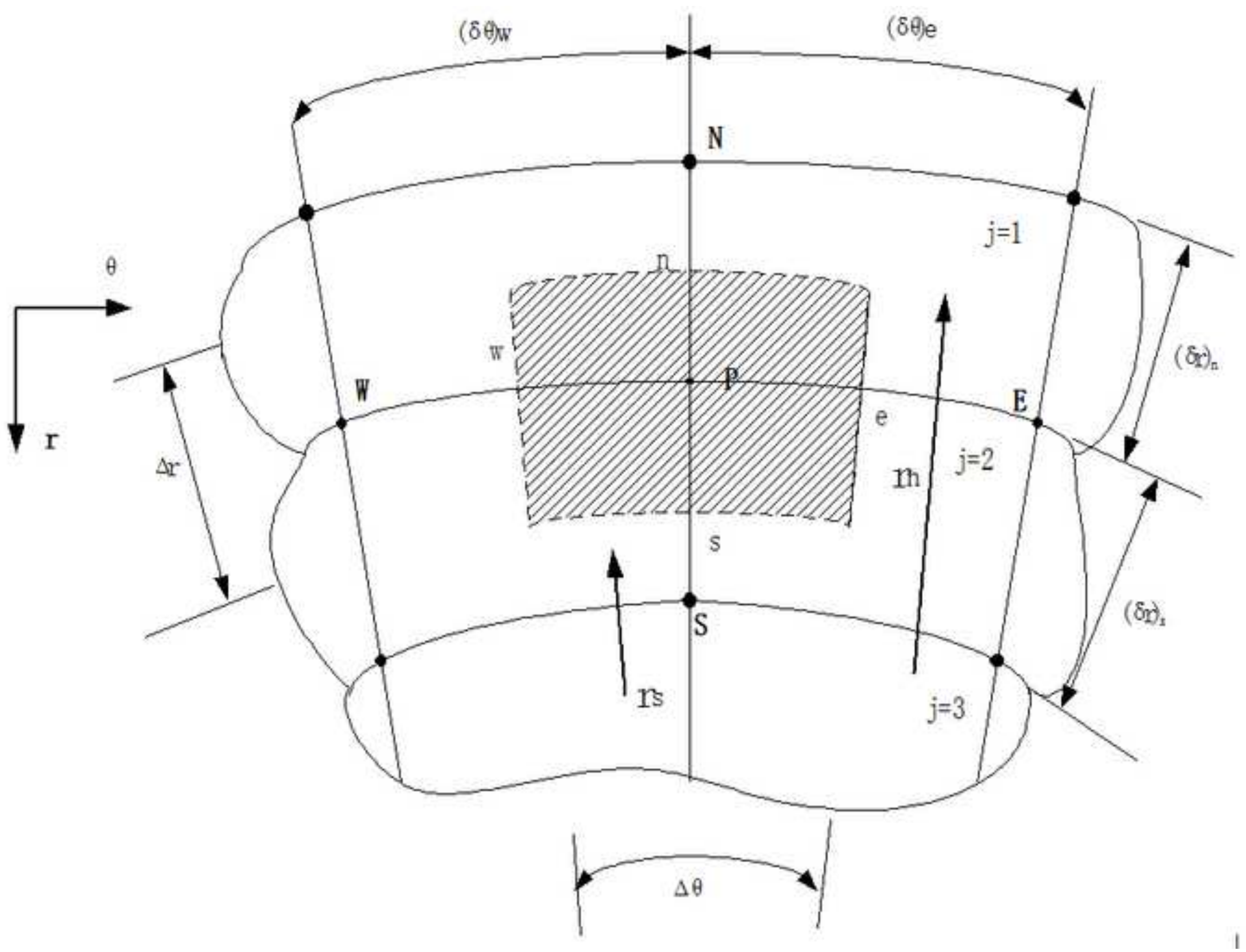




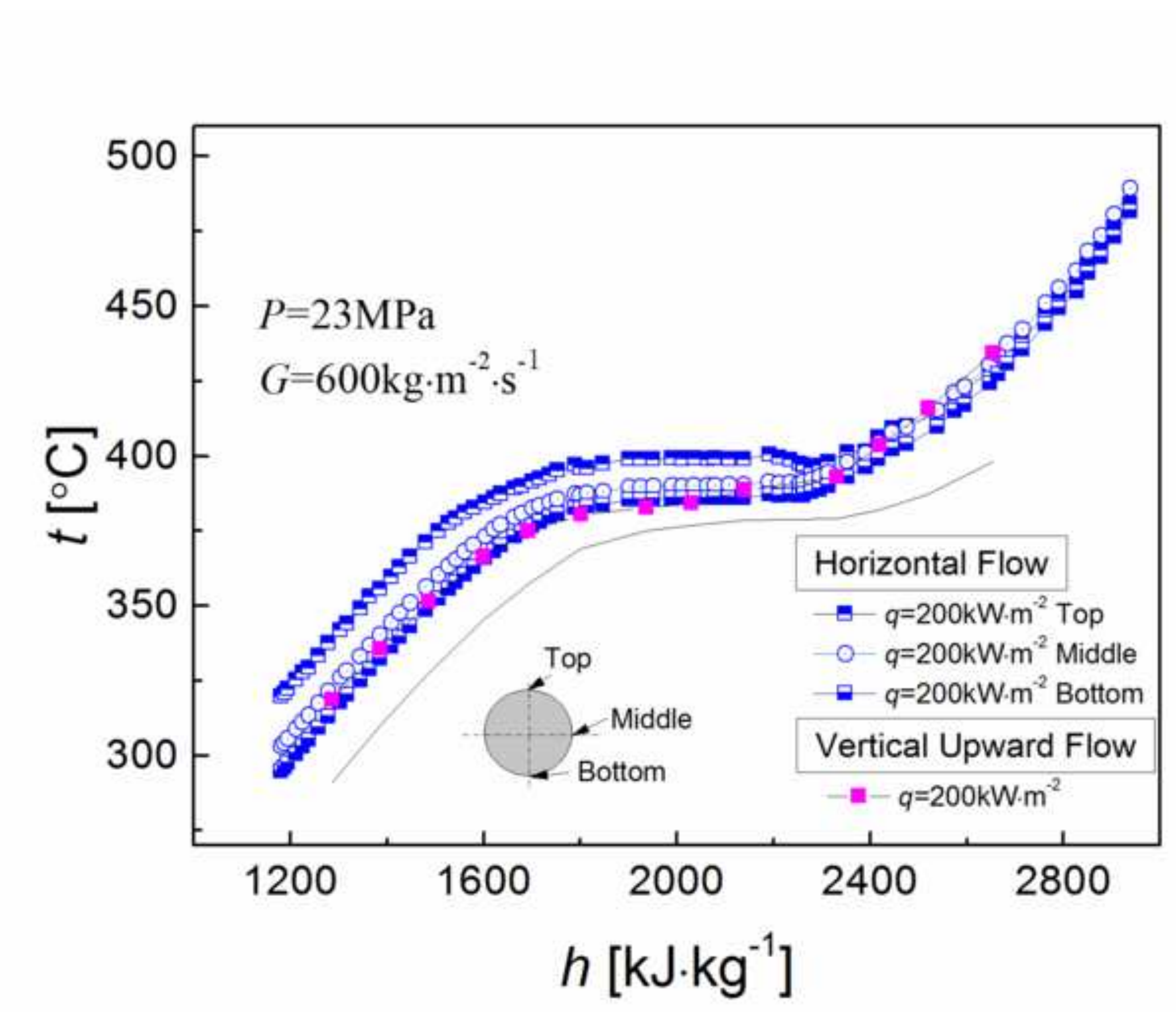




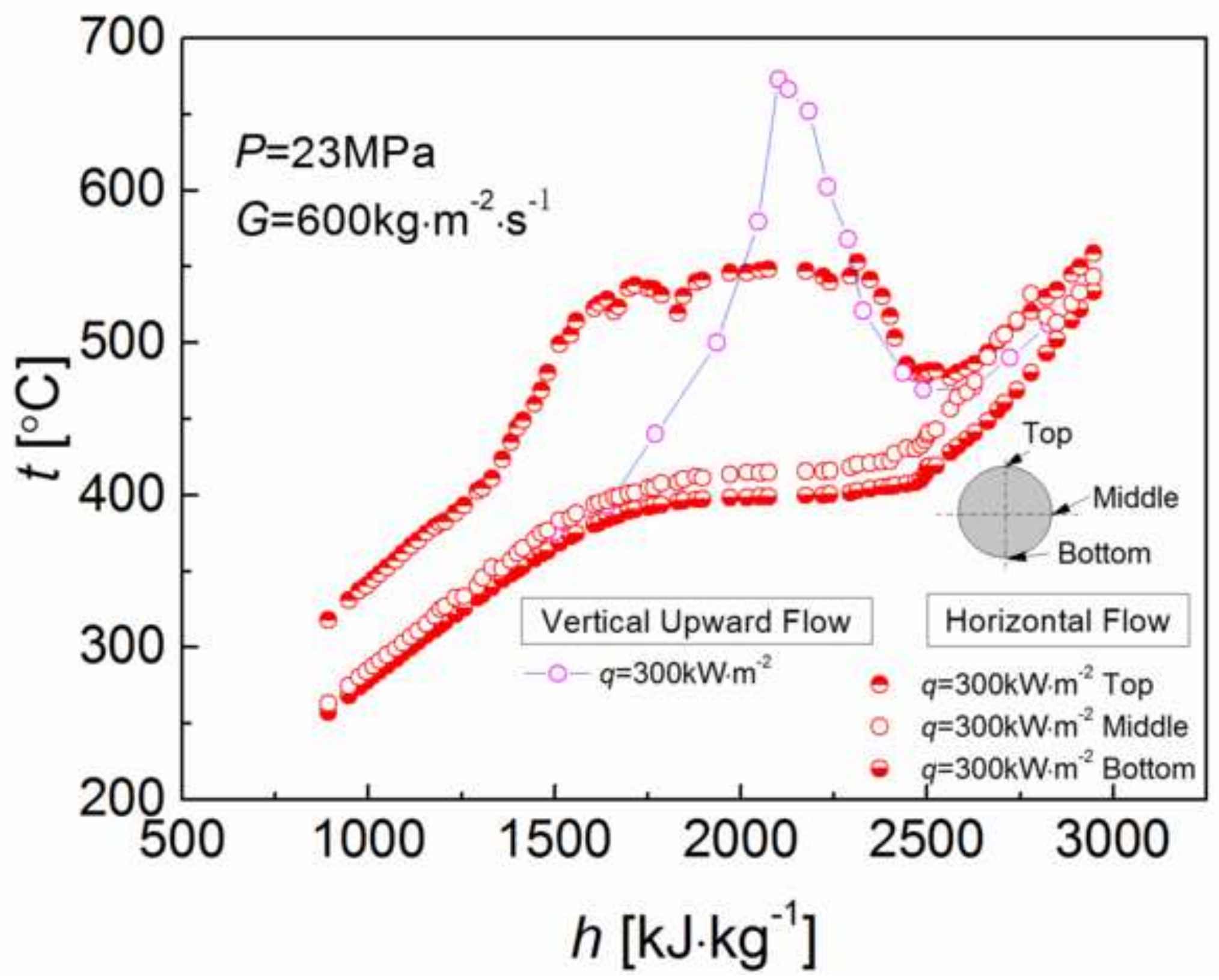




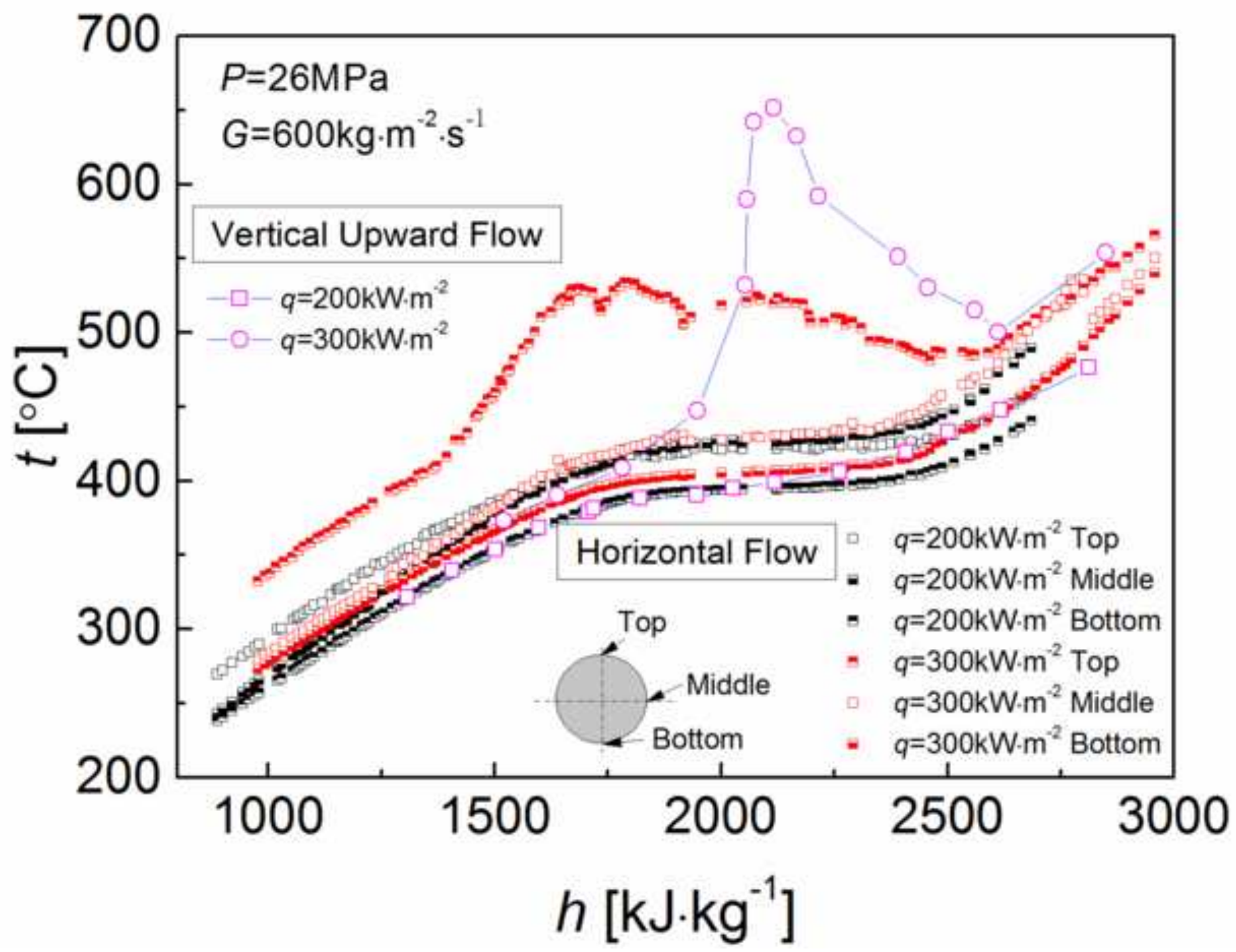




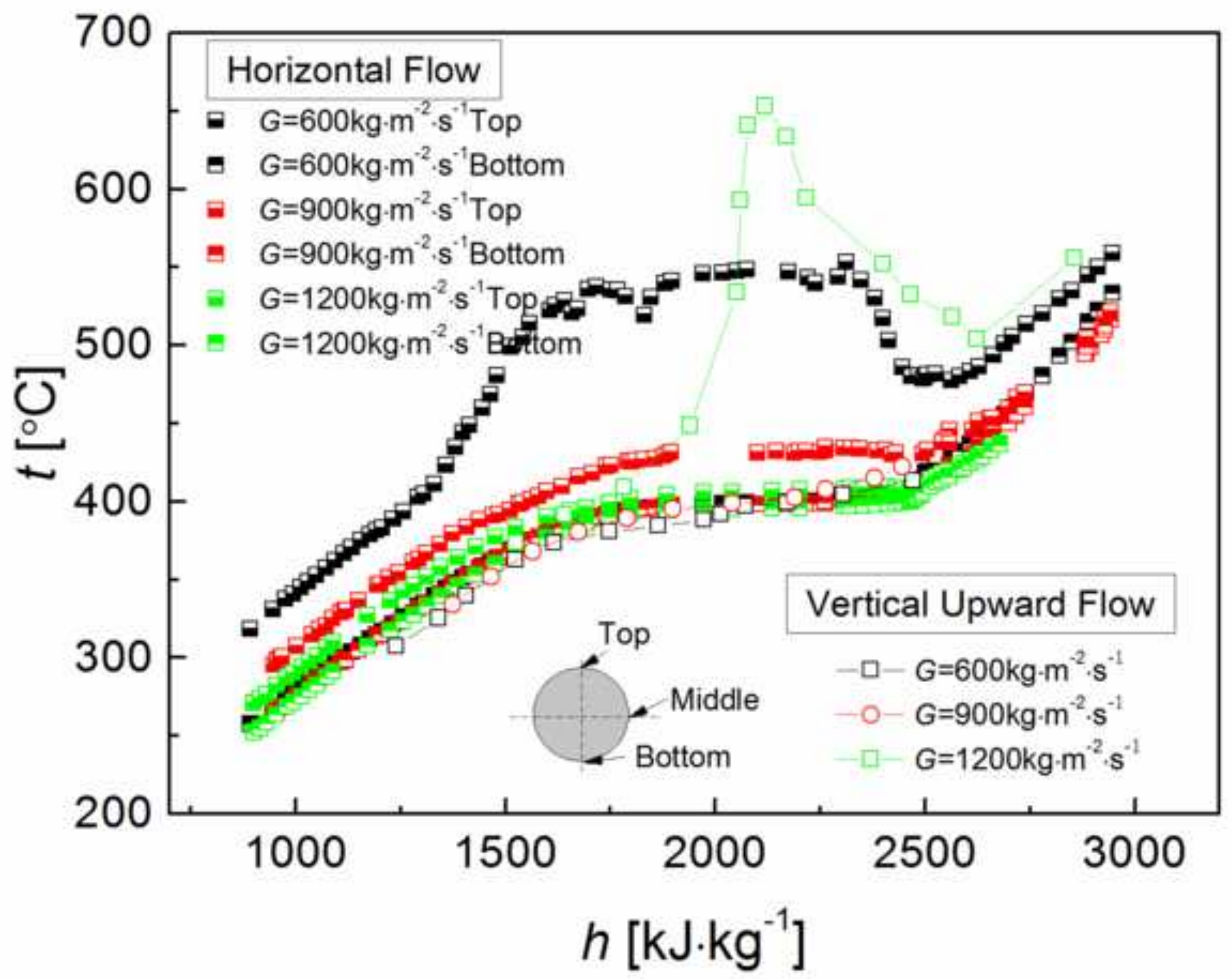




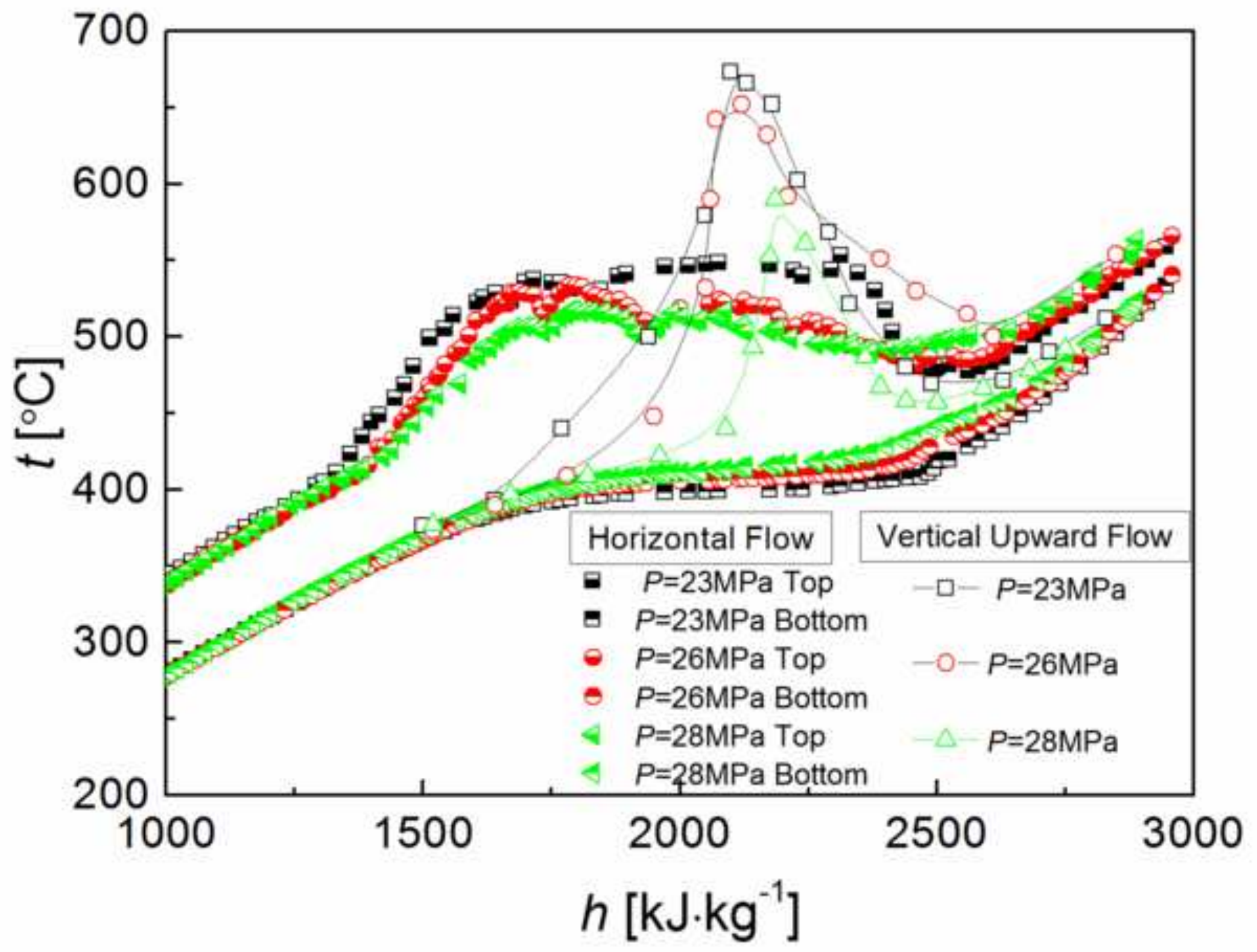




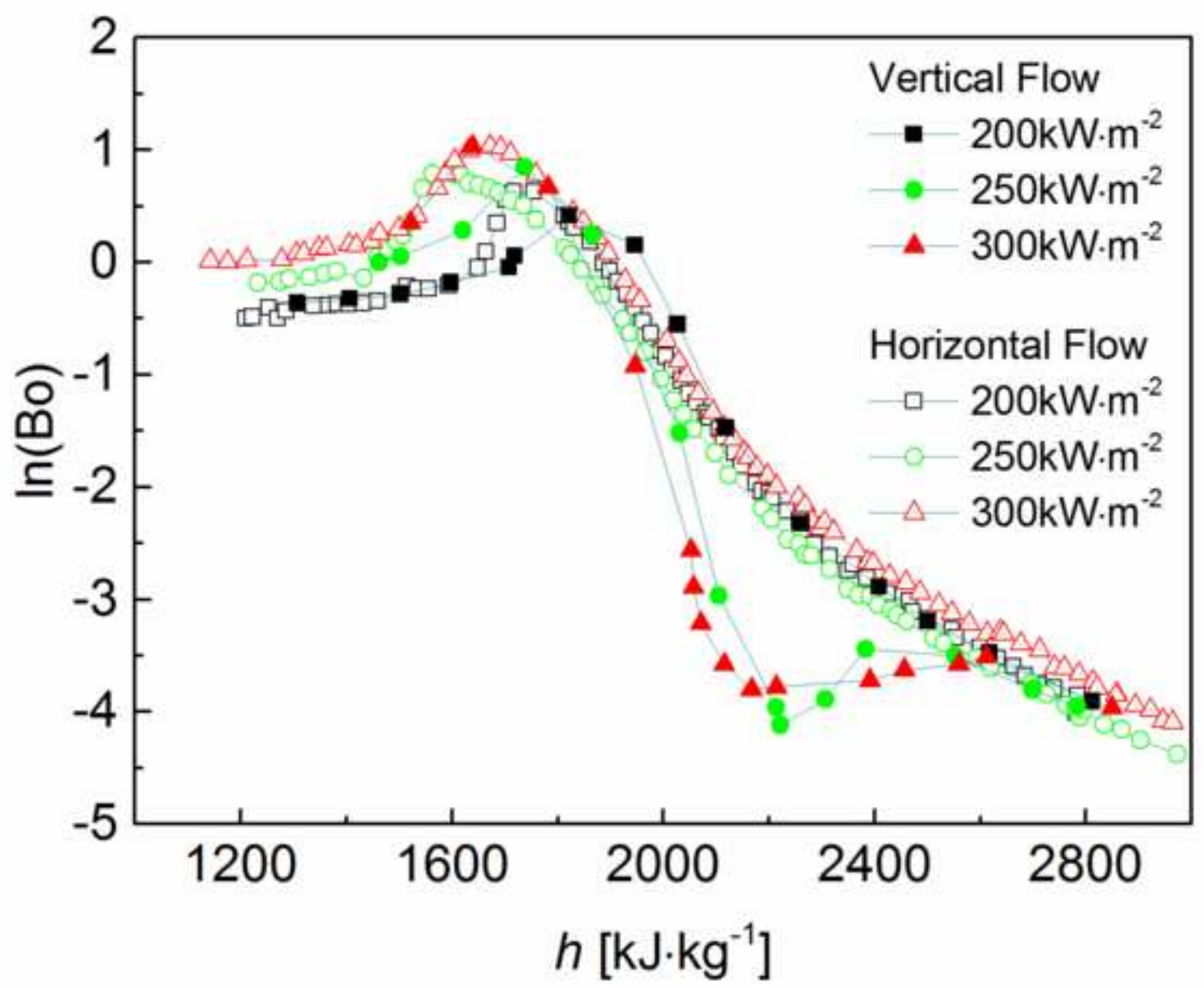




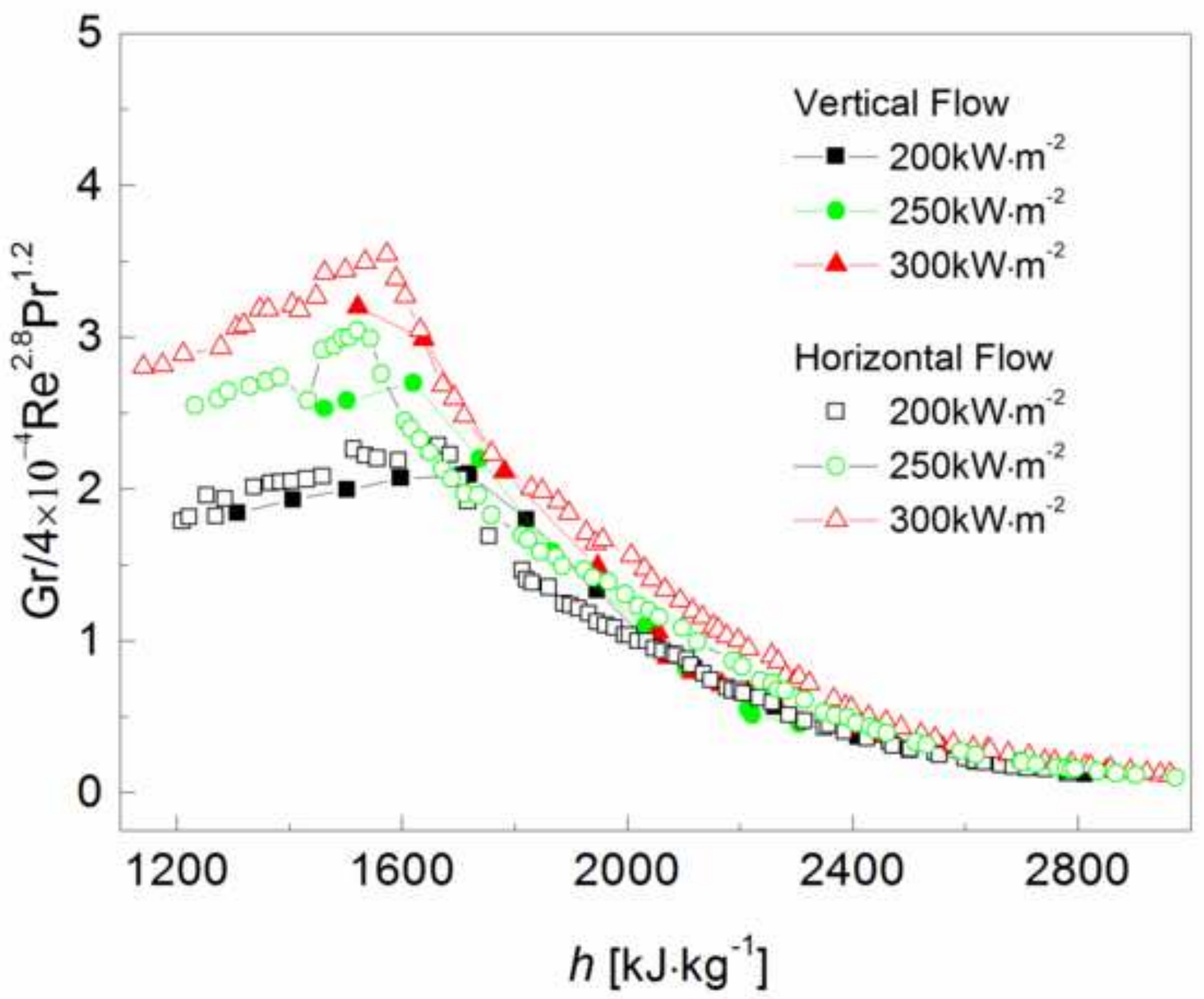




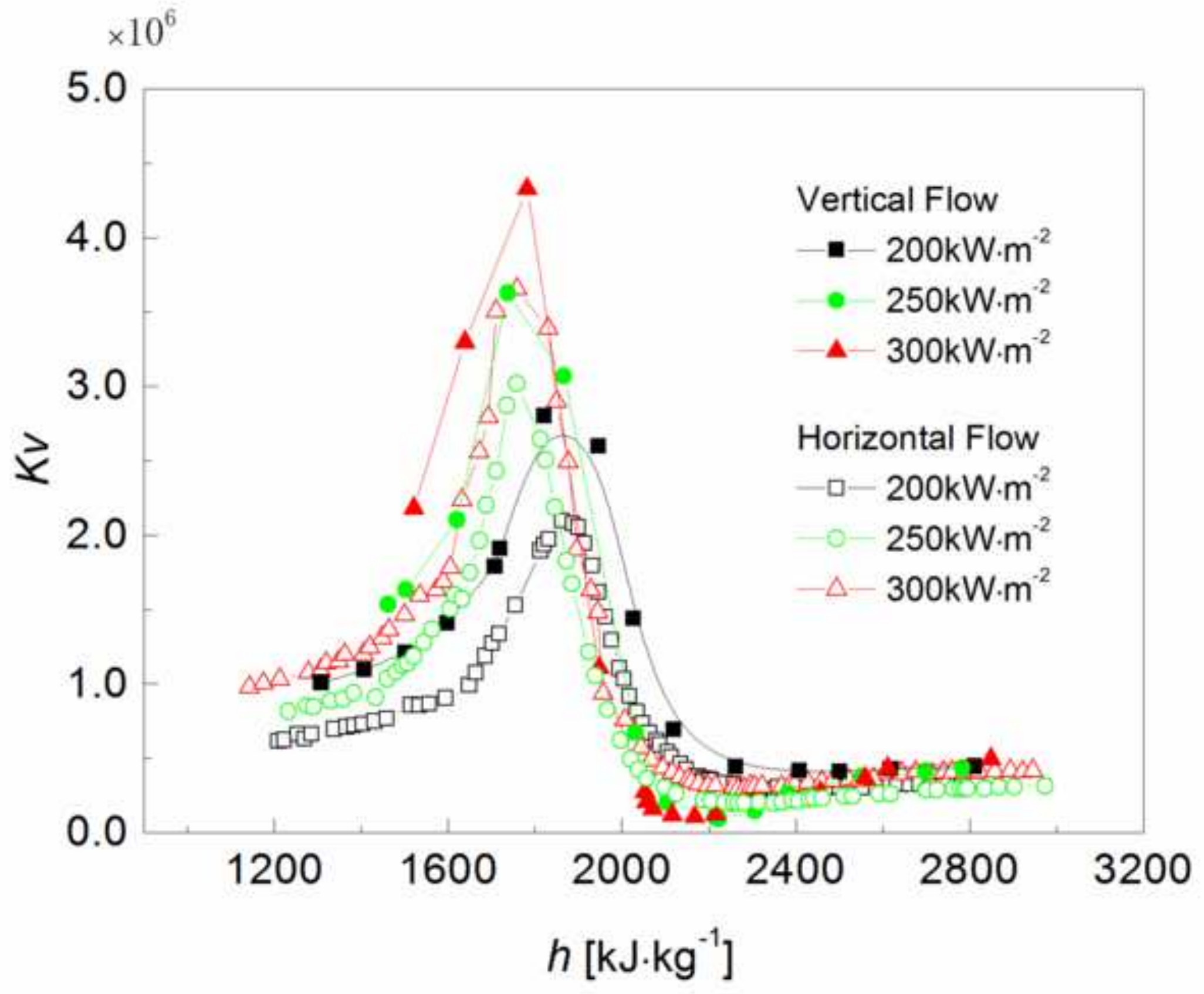




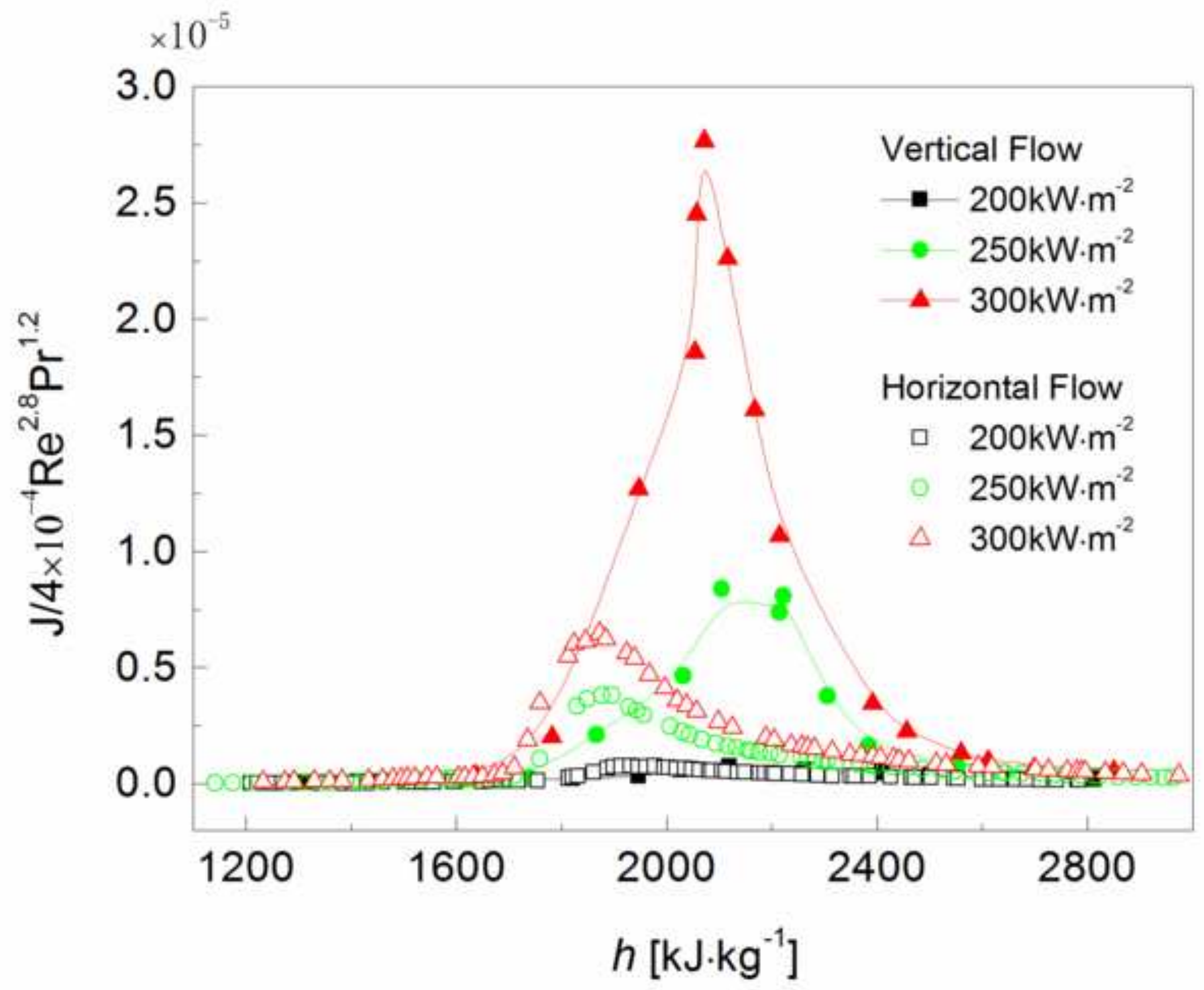




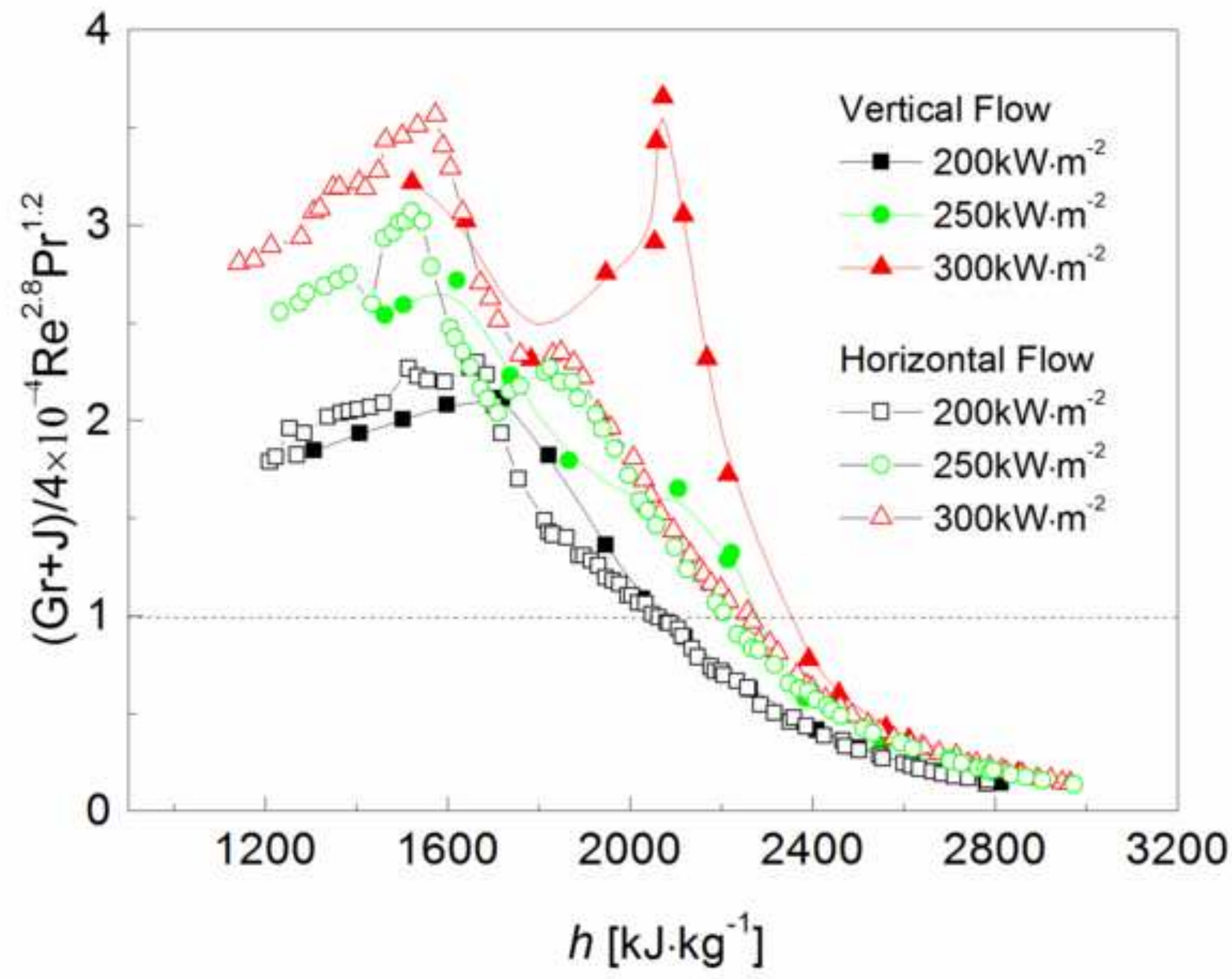




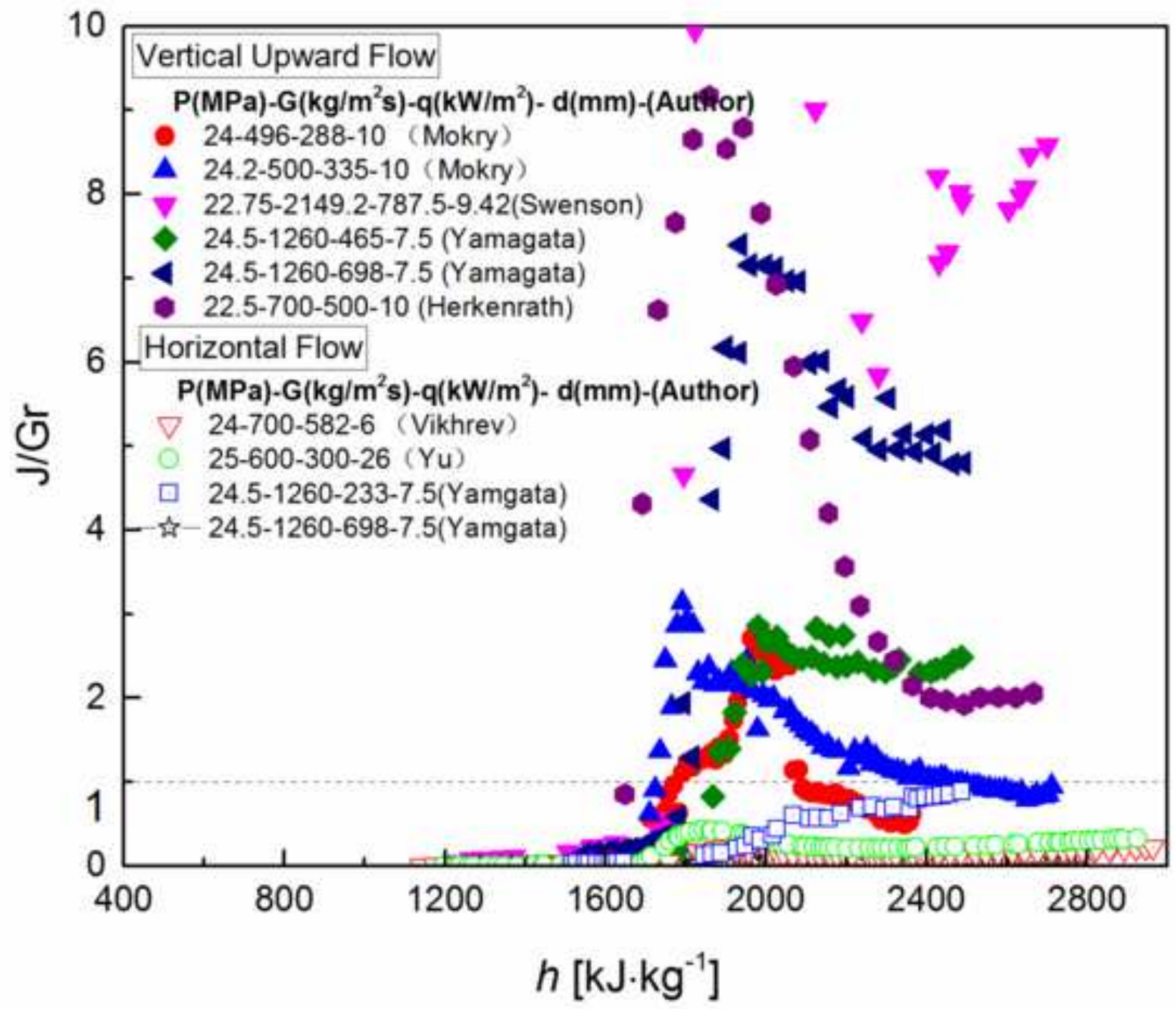


Graphical abstract

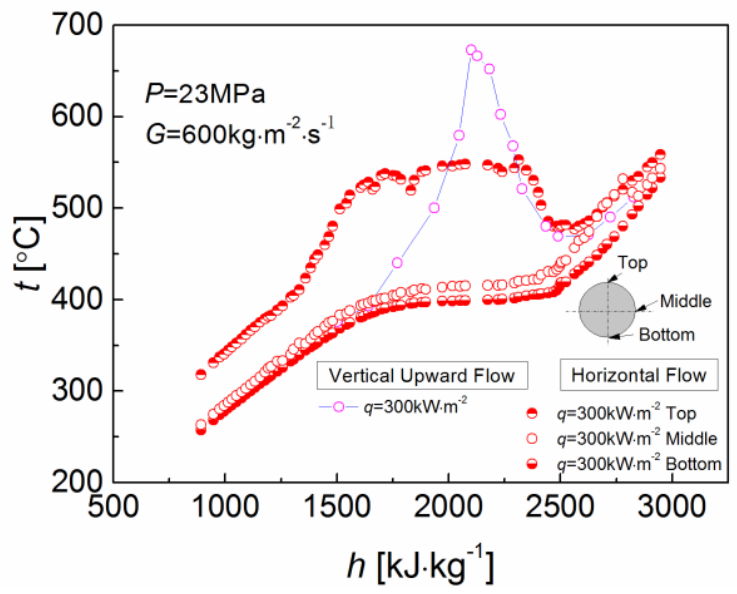

